\title{
Phosphorylation of NF-kBp65 drives inflammation-mediated hepatocellular carcinogenesis and is a novel therapeutic target
}

Xuan $\mathrm{Xu}^{1,2+}$, Yiming Lei ${ }^{1,2+}$, Lingjun Chen ${ }^{1,2}$, Haoxiong Zhou ${ }^{1,2}$, Huiling Liu ${ }^{1,2}$, Jie Jiang ${ }^{1,2}$, Yidong Yang ${ }^{1,2^{*}}$ and $\operatorname{Bin} \mathrm{Wu}^{1,2^{*}}$

\begin{abstract}
Background: Nuclear factorkB (NF-kB) plays a vital role in hepatocellular carcinoma (HCC). $\beta$-arrestin1 (ARRB1) has been proved to enhance the activity of NF-KBp65, and our previous study indicated that ARRB1 promotes hepatocellular carcinogenesis and development of HCC. However, it remains unknown whether p65 is involved in hepatocellular carcinogenesis through the ARRB1-mediated pathway.

Methods: The levels of NF-KBp65 and NF-KBp65 phosphorylation ( $p$-p65) were assessed in including normal liver, primary HCC and paired paracancerous tissues. Liver-specific p65 knockout mice were used to examine the role of p65 and p-p65 in hepatocarcinogenesis. The mechanism of NF-kBp65 and p-p65 in hepatocarcinogenesis via ARRB1 was also studied both in vitro and in vivo.

Results: Phosphorylation of NF-KBp65 was markedly upregulated in inflammation-related HCC patients and was significantly increased in mouse hepatic inflammation models, which were induced by tetrachloromethane $\left(\mathrm{CCl}_{4}\right)$, diethylnitrosamine (DEN), TNF-a, as well as DEN-induced HCC. Hepatocyte-specific p65-deficient mice markedly decreased in the HCC incidence and size of tumours by the repressing of the proliferation of malignant cells in a DEN-induced HCC model. Furthermore, ARRB1 directly bounds p65 to promote the phosphorylation of NF-KBp65 at ser536, resulted in cell malignant proliferation through GSK3ß/mTOR signalling.

Conclusion: The data demonstrated that phosphorylation of NF-kBp65 drives hepatocellular carcinogenesis in response to inflammation-mediated ARRB1, and that inhibition of the phosphorylation of NF-kBp65 restrains the hepatocellular carcinogenesis. The results indicate that phosphorylation of NF-KBp65 is a novel therapeutic target for HCC.
\end{abstract}

Keywords: Hepatocellular carcinoma, Inflammation, NF-KBp65, Phosphorylation, $\beta$-arrestin1

\footnotetext{
*Correspondence: yangyd6@mail.sysu.edu.cn; wubin6@mail.sysu.edu.cn

${ }^{+}$Xuan Xu and Yiming Lei contributed equally to this work.

'Department of Gastroenterology, the Third Affiliated Hospital of Sun Yat-Sen

University, Guangzhou 510630, Guangdong Province, China

Full list of author information is available at the end of the article
}

(c) The Author(s). 2021 Open Access This article is licensed under a Creative Commons Attribution 4.0 International License, which permits use, sharing, adaptation, distribution and reproduction in any medium or format, as long as you give appropriate credit to the original author(s) and the source, provide a link to the Creative Commons licence, and indicate if changes were made. The images or other third party material in this article are included in the article's Creative Commons licence, unless indicated otherwise in a credit line to the material. If material is not included in the article's Creative Commons licence and your intended use is not permitted by statutory regulation or exceeds the permitted use, you will need to obtain permission directly from the copyright holder. To view a copy of this licence, visit http://creativecommons.org/licenses/by/4.0/ The Creative Commons Public Domain Dedication waiver (http://creativecommons.org/publicdomain/zero/1.0/) applies to the data made available in this article, unless otherwise stated in a credit line to the data. 


\section{Background}

Hepatocellular carcinoma (HCC), the most common neoplasm among all primary liver cancers, is currently the sixth most common malignancy and the second leading cause of cancer-related death worldwide [1, 2]. Numerous results have demonstrated that chronic inflammation is connected to hepatocarcinogenesis, and chronic inflammation caused by persistent infections with hepatitis $B$ virus (HBV) and hepatitis $\mathrm{C}$ virus $(\mathrm{HCV})$ or nonalcoholic steatohepatitis (NASH) can increase cancer risk [3].

Nuclear factorkB $(\mathrm{NF}-\kappa \mathrm{B})$ is activated in response to different infectious agents and inflammatory cytokines, and it plays a central role in inflammation control and immunosuppression via several mechanisms [4]. The mammalian NF- $\mathrm{kB}$ family consists of five transcription factors: p65 (also known as RelA), RelB, c-Rel, p105/p50 (NF-kB1), and p100/p52 (NF-кB2). Although p65, RelB and $\mathrm{c}-\mathrm{Rel}$ are final proteins, p50 and p52 are produced by proteolytic processing of p105 and p100 [5]. All transcription factors are activated only when they form heterodimers or homodimers and induce nuclear translocation after a series of stimulations, among which RELA-p50 is most commonly detected and takes charge of the most transcriptional activity [4]. Inhibitor of $\mathrm{kB}$ (I $\mathrm{B}$ ) proteins can inhibit the activation of NF- $\mathrm{KB}$ dimers by interacting with the nuclear localization signal (NLS) of the highly conserved Rel homology domain (RHD), inducing a shift from the cytoplasm to the nucleus. However, I $\mathrm{KBs}$ are regulated by the IкB kinase (IKK) complex, which is composed of two catalytic subunits, $\mathrm{IKK} \alpha$ and IKK $\beta$, and a regulatory component called $\mathrm{IKK} \gamma$ or NF- $\mathrm{B}$ essential modulator (NEMO). Many stimuli activate NF- $\mathrm{B}$ through IKK-dependent phosphorylation, causing degradation of $\mathrm{I} K \mathrm{Bs}[4,6,7]$. Previous studies have established IKK $\beta$-deficient mice and demonstrated that inactivation of the IKK-NF- $\mathrm{kB}$ pathway can attenuate the promotion of a colitis-associated cancer model [8]. NF- $\mathrm{kB}$ was found to be activated in human $\mathrm{HCC}$, especially hepatitis-related human $\mathrm{HCC}$ [9]. The activation of NF- $\mathrm{B}$ in solid malignancies was due to increased activation of IKK cytokines, including tumour necrosis factor (TNF) and IL1 $[10,11]$.

$G$ protein-coupled receptors (GPCRs), the largest family of membrane proteins, play critical roles in mediating physiological responses and activation of crosstalk signalling related to human cancer [12]. According to a previous view, GPCR signalling couples to the $G$ protein and triggers canonical transduction cascades, while $\beta$ arrestin1 (ARRB1) can be recruited and results in GPCR desensitization [13]. The dominant role of ARRB1 is to dampen the activity of NF- $\kappa B$ by binding to $\mathrm{I} \kappa \mathrm{Bs}[14$, 15]. Our previous study also found that ARRB1 is involved in hepatocarcinogenesis via the PI3K/Akt pathway [16]. Certain studies have confirmed the role of ARRB1 in tumorigenesis, including nicotine-induced carcinogenesis in the lungs by nuclear translocation of ARRB1 and LPA-induced breast cancer through ARRB1mediated cell migration and invasion $[17,18]$.

Akt, also known as protein kinase $\mathrm{B}$, is a serine/threonine protein kinase that mediates several cellular functions, including cell growth and proliferation, through phosphatidylinositol 3-kinase (PI3K). Akt is frequently activated in human solid tumours, including HCC [16]. Glycogen synthase kinase $3 \beta$ (GSK3 $\beta$ ), a serine/threonine protein kinase, is found to induce the phosphorylation of diverse substrates and to be one of the first identified substrates of kinase Akt. Inhibition of GSK3 $\beta$ caused by phosphorylation of the Ser9 site can deactivate GSK3 $\beta$ through Akt signalling and stabilize downstream target proteins by inhibiting ubiquitin/proteasome-mediated degradation [19]. Several reports have also found that GSK3 $\beta$ plays a critical role in the promotion of HCC and can increase proteins related to cell growth through phosphorylation of mTOR [20].

Previous studies have indicated that both ARRB1 and the activated NF- $\mathrm{BB}$ pathway are related to inflammation-related HCC. However, whether activated NF- $\mathrm{KB}$ signalling is involved in ARRB1-mediated hepatocarcinogenesis remains unknown. In our study, these data showed that phosphorylation of NF- $\mathrm{kBp} 65$ is induced in HCC patients and that enhanced ARRB1 directly induces the phosphorylation of p65 by binding. Together, our data suggested that phosphorylation of p65 is related to ARRB1-mediated hepatocellular carcinogenesis via GSK3 $\beta / \mathrm{mTOR}$ and that inhibitors of NF-kBp65 could be therapeutic targets for HCC.

\section{Materials and methods}

\section{Clinical samples, tissue microarray and microarray experiment}

This study was approved by the Clinical Research Ethics Committee of the Third Affiliated Hospital of Sun YatSen University. All of the patients were informed of the use of their data before surgery was performed. Specimens of primary $\mathrm{HCC}$ and paired paracancerous tissues were obtained from HCC patients who received curative surgery at the Third Affiliated Hospital of Sun Yat-Sen University. Normal liver tissues were obtained from adjacent tissues in haemangioma patients who received hepatectomy. Samples were used for tissue microarray. Whole blood $(3 \mathrm{ml})$ from healthy volunteers and HBVinfected HCC patients was collected by venepuncture. After static duration for $30 \mathrm{~min}$ at room temperature, samples were centrifuged for $15 \mathrm{~min}$ at $2000 \mathrm{~g}$. The serum was obtained and stored at $-80^{\circ} \mathrm{C}$ for further determination of total protein. The gene expression experiments were performed as described previously [16]. 


\section{Cell culture and establishment of cell lines}

HepG2 and Hep3B cells were obtained from the American Type Culture Collection (ATCC, Manassas, VA, USA). HepG2, Hep3B and HepG2.2.15 cells were cultured in Dulbecco's modified Eagle's medium (DMEM) (Gibco BRL, Rockville, MD, USA) supplemented with $10 \%$ foetal bovine serum (FBS) (Gibco BRL) in an incubator with $5 \% \mathrm{CO}_{2}$ at $37^{\circ} \mathrm{C}$. LO2 cells were cultured in RPMI 1640 medium (Gibco BRL) with 10\% FBS. For activator intervention, LO2, HepG2, Hep3B and HepG2.2.15 cells were treated with TNF- $\alpha(40 \mathrm{ng} / \mathrm{ml})$ purchased from Proteintech Group (Rosemont, IL, USA) for $4 \mathrm{~h}$. For the NF-kB inhibitor, $10 \mu \mathrm{M}$ Bay 11-7082 (Sigma, St Louis, MO, USA) was added to the cell lines $6 \mathrm{~h}$ after $2 \mathrm{~h}$ of pretreatment with TNF- $\alpha(40 \mathrm{ng} / \mathrm{ml})$. The lentiviral vector encoding the human $A R R B 1$ gene was purchased from GeneChem (Shanghai, China) Corp. We transfected the cells with the ARRB1 lentivirus according to the instructions and obtained stable ARRB1expressing LO2, HepG2, Hep3B and HepG2.2.15 cell lines by puromycin selection $(2 \mu \mathrm{g} / \mathrm{ml})$. We also purchased p65 wild type (WT) and p65 mutant (S536A), of which serine 536 could not be phosphorylated as inactive p-p65, while p65 mutant (S536E) could mimic phospho-p65 as active p-p65.

\section{Mice}

The study was approved by the Institutional Animal Care and Use Committee of the Third Affiliated Hospital of Sun Yat-Sen University. Hepatocyte-specific $p 65$ knockout $(L-p 65 \mathrm{KO})\left(\mathrm{p} 65^{\mathrm{f} / \mathrm{f}}, \mathrm{Alb}-\mathrm{cre}^{+/-}\right)$mice were obtained by crossing floxed-p65 littermate $\left(\mathrm{p} 65^{\mathrm{f} / \mathrm{f}}\right)$ mice with Alb-cre ${ }^{+/-}$mice as described previously [21]. Floxed-p65 littermates $\left(\mathrm{p} 65^{\mathrm{f} / \mathrm{f}}\right)$ were used as wild-type (WT) mice. WT mice and $L-p 65-\mathrm{KO}$ mice were produced by heterozygote intercrosses on a C57BL/6 background. The mice were housed in microisolator cages under a 12/12-h dark-light cycle (lights on at 8:00 a.m.) with food and water ad libitum. The sedative consisted of xylazine $(15 \mathrm{mg} / \mathrm{kg})$, and ketamine $(50 \mathrm{mg} / \mathrm{kg})$ was administered intraperitoneally as anaesthesia. Carbon dioxide inhalation was used as the method of euthanasia. Animal research protocols were authorized by the Institutional Animal Care and Use Committee of the Third Affiliated Hospital of Sun Yat-Sen University.

\section{Treatment of mice}

All of the studies were conducted in at least 6 male mice in each group following the protocol described previously $[16,22]$. For tetrachloromethane $\left(\mathrm{CCl}_{4}\right)$-induced mouse liver cirrhosis models, 6- to 8-week-old mice were intraperitoneally injected with $\mathrm{CCl}_{4}$ (Sigma, St Louis, MO, USA) at $5 \mathrm{mg} / \mathrm{kg}$ twice per week. $\mathrm{CCl}_{4}$ was dissolved in olive oil (Macklin Biochemical, Shanghai,
China) at a ratio of $1: 4$, and vehicle mice were injected with olive oil. The mice were sacrificed 8 weeks after injection. For diethylnitrosamine (DEN)-induced hepatitis models, 6- to 8-week-old mice received an intraperitoneal injection of DEN (100 mg/kg) (Sigma, St Louis, MO, USA). The mice were sacrificed 10 days after injection, and vehicle mice were injected with physiological saline at an equivalent volume. For TNF- $\alpha$-induced acute liver inflammation models, 6- to 8-week-old mice were intraperitoneally injected with TNF- $\alpha$ dissolved in cell culture medium (DMEM) $6 \mathrm{~h}$ before being sacrificed. For the DEN-induced HCC model, 14-day-old mice were treated with an intraperitoneal injection of DEN $(15 \mathrm{mg} / \mathrm{kg})$. The tumour incidence was analysed 9 months after injection, and the tumour nodules were measured with Vernier callipers.

\section{MRI scans in DEN-induced HCC mouse model}

Nine months after DEN injection, mice were anaesthetized with isoflurane at room temperature. The mice were placed in a 7.0 T MRI tomograph (PharmaScan70/ 16, Bruker BioSpin, Ettlingen, Germany) with continuous narcosis. The respiratory and heart rates of the mice were monitored during MRI imaging.

\section{Protein extraction and western blotting}

Total protein extracts from normal tissues, HCC liver tissues and cell lysates were obtained by RIPA buffer treatment and examined via western blotting as described previously [16]. Blots were imaged using ChemiDoc imaging system (Bio-rad, Hercules, CA, USA). Serum proteins were diluted 50 times before being subjected to western blotting. Antibodies against p65 (1: 1000, 8242, CST, Danvers, MA, USA), p-p65 (1:1000, 3033, CST), PCNA (1:2000, 13,110, CST), ARRB1 (1: $1000,12,697$, CST), TNF- $\alpha$ (1:1000, 6945, CST), PI3K (1: 1000, 4249, CST), Akt (1:1000, 9272, CST), p-Akt (1: 1000, 4060, CST), GSK3ß (1:1000, 12,456, CST), pGSK3 $\beta$ (1:1000, 9323, CST), mTOR (1:1000, 2983, CST), p-mTOR $(1: 1000,5536$, CST) and $\beta$-actin (1:3000, A5441, Sigma-Aldrich, St Louis, MO, USA) were used as primary antibodies. Goat anti-mouse (1:5000, 7076, CST) or goat anti-rabbit (1:5000, 7074, CST) HRPlinked antibodies were used as secondary antibodies. After quantifying the densitometry of each target protein and $\beta$-actin, the results were expressed as normalized ratios.

\section{Co-immunoprecipitation assay (co-IP assay)}

For the co-IP assay, ARRB1-overexpressing HepG2 cells and TNF- $\alpha$ pretreatment HepG2 cells were used to obtain protein lysates. Protein A-Magnetic Beads $(100 \mu \mathrm{l})$ were conjugated with antibodies against GFP, ARRB1 and IgG (CST) at room temperature for $1 \mathrm{~h}$. The cell 
lysates were cleared, and preconjugated magnetic beads were added to the supernatant to pull the immune complexes by spinning them at $4{ }^{\circ} \mathrm{C}$ overnight. The beads were washed three times with $0.1 \%$ PBS, soaked in lysis buffer and heated for $10 \mathrm{~min}$ at $70{ }^{\circ} \mathrm{C}$. The supernatant was subjected to western blotting assay as described previously with ARRB1-, p65- and p-p65-specific antibodies (CST).

\section{Immunohistological staining, immunofluorescence staining and EdU cell proliferation assay}

Liver sections were subjected to $H \& E$ staining and immunohistochemical (IHC) staining according to the protocol in our previous study [16]. Immunofluorescence (IF) staining of HCC cell lines was also performed as previously described [16]. For IHC staining, antibodies against p65 (1:200, 8242, CST), p-p65 (1:200, SAB4300009, Sigma), NF-кB1 (1:100, A6667, Abclonal, Woburn, MA, USA), p-NF-кB1 (1:100, AP0417, Abclonal), NF-кB2 (1:100, A3108, Abclonal), p-NF-кB2 (1:100, AP0418, Abclonal), RELB (1:100, A0519, Abclonal), pRELB (1:100, AP0240, Abclonal), c-Rel (1:100, GTX113264, GeneTex, Irvine, CA, USA), p-c-Rel (1:100, ab30624, Abcam, Cambridge, MA, USA), Ki67 (1:400, ab15580, Abcam), ARRB1 (1:100, Abcam ab32099), pAkt (1:100, CST), and p-GSK3 $\beta$ (1:200, CST) were used as primary antibodies. The EnVision method (EnVision Kit/Alakline Phosphatase detection system, DAKO, Glostrup, Denmark) was used, and haematoxylin was used for liver section counterstaining. For cell IF staining, after fixation, permeabilization and incubation with specific primary antibodies against p65, fluorescenceconjugated secondary antibodies Alexa 594 (Molecular Probes, Eugene, OR, USA) and DAPI (Molecular Probes) were performed. Images were analysed using fluorescence microscopy. An EdU DNA Cell Proliferation Kit (RiboBio, Guangzhou, Guangdong province, China) was used to assess cell proliferation and was performed according to the manufacturer's protocol. The nuclei of proliferative cells were dyed red. For double staining of p65 and EdU, IF staining of cells was performed before the EdU assay, and the EdU index was calculated as follows: the number of red nuclei / the number of total cells.

\section{Cell viability and colony formation assay}

To evaluate cell growth, a CCK-8 assay (Dojindo Laboratories, Kumamoto, Japan) was used. Cells $\left(1 \times 10^{3}\right.$ cells) were seeded in 96-well plates per well with $100 \mu \mathrm{l}$ of complete medium overnight. Following Bay 11-7082 inhibitor incubation for 24 to $96 \mathrm{~h}$, Cell Counting Kit-8 (CCK-8) solution $(10 \mu \mathrm{l})$ was then added to each well and incubated for $2 \mathrm{~h}$ at $37^{\circ} \mathrm{C}$ before measuring OD values at an absorbance of $450 \mathrm{~nm}$ at each time point
(BioTek, Winooski, VT, USA). For the colony formation assay, cells $\left(1 \times 10^{3}\right.$ cells $)$ were seeded in 6 -well plates per well. Following 14 days of incubation with a low dose of Bay 11-7082 inhibitor, the cells were washed, fixed and stained with crystal violet. All of the cells were seeded in triplicate wells, and all of the experiments were performed three times.

\section{Xenograft tumours}

Xenograft tumours were established in 4-week-old male Balb/c nude mice purchased from Vital River Laboratory Animal Technology Co., Ltd. (Beijing, China). Approximately $1 \times 10^{6}$ Hep3B cells were injected subcutaneously into nude mice, and tumour growth was recorded at each time point. The tumour volume was calculated by the formula (length $\times$ width $^{2} / 2$ ), and the tumour was supposed to be established when the length and width were both more than $5 \mathrm{~mm}$. The nude mice were equally divided into two groups according to the volume and treated with an intraperitoneal injection of PDTC (an NF-kB inhibitor, $120 \mathrm{mg} / \mathrm{kg}$ ) (Sigma) once per day for 12 days, and tumour growth was recorded every 3 days after the first injection of inhibitor.

\section{Real-time PCR analysis}

Total RNA was extracted using a Tissue RNA Purification Kit RN002 (ES Science, Shanghai, China) and transcribed into cDNA using a High Capacity cDNA Kit FSQ101 (TOYOBO, Osaka, Japan). For quantitative realtime polymerase chain reaction (PCR) analysis, aliquots of CDNA were amplified using gene-specific primers and ChamQ SYBR qPCR Master Mix (Vazyme, Nanjing, Jiangsu province, China) in a real-time PCR system (BioRad). Each sample was tested in triplicate. RNA was amplified using the following primers: Human $p 65$ exon sense 5' - ATGTGGAGATCATTGAGCAGC-3', and human $p 65$ exon antisense $5^{\prime}$ - CCTGGTCCTGTGTA GCCATT-3'; mouse $p 65$ exon sense 5 '-TGCGATTCCG CTATAAATGCG-3', and mouse $p 65$ exon antisense $5^{\prime}$ ACAAGTTCATGTGGATGAGGC-3'; mouse TNF- $\alpha$ exon sense $5^{\prime}$-CTTCATCACCTATCCCTCGAC-3' and mouse TNF- $\alpha$ exon antisense $5^{\prime}$-CTGGCTATTTGCTT CTTGTCCT-3'. The expression of $\beta$-actin was quantified as the internal control using the sense primer $5^{\prime}$ GTCTTCCCCTCCATCGTG-3' and the antisense primer 5'-AGGGTGAGGATGCCTCTCTT-3' for human samples, and the sense primer $5^{\prime}$-GGCTGTATTCCCCT CCATCG-3' and the antisense primer $5{ }^{\prime}$-CCAGTTGG TAACAATGCCATGT-3' for mouse samples.

\section{Analysis of p65 and p-p65 translocation}

To analyse p65 and p-p65 translocation into the nucleus, samples of cell lines or an aliquot of liver tumour cells isolated from the DEN-induced HCC mouse model was 
collected. Then, nuclear and cytoplasmic fractions were isolated using the Nuclear Extract Kit (Active Motif, Carlsbad, CA, USA) according to the manufacturer's protocol. Aliquots of both fractions were mixed with equal volumes of $2 \times$ Laemmli sample buffer and analysed by western blotting for p65 and p-p65.

\section{P65 and ARRB1 reporter assays}

Two hundred ninety-three $\mathrm{T}$ cells $\left(2 \times 10^{4} /\right.$ well $)$ were plated in 24-well plates and transfected with the expression plasmid pcDNA3.1- p65 (WT)-HA or pcDNA3.1p65 (S536A)-HA or pcDNA3.1- p65 (S536E)-HA or the vector pcDNA3.1-HA (400 ng/well) using Lipofectamine 3000 (L3000, Invitrogen, Carlsbad, CA, USA). For each transfection, $200 \mathrm{ng}$ of the pGL4.1-p65 luciferase reporter plasmid or the pGL4.1-ARRB1 luciferase reporter plasmid, combined with $5 \mathrm{ng}$ of the Renilla plasmid as a control, was used. Luciferase activities were detected by the Dual-Luciferase Reporter Assay System (E1910, Promega, Fitchburg, WI, USA) according to the manufacturer's instructions with a Lumat LB 9507 luminometer (Berthold, Nashua, NH, USA).

\section{Statistical analyses}

The results are presented as the means \pm standard deviation (SD). The significance of variables of two groups was determined by the independent-samples t-test. The protein levels of p-p65 in normal liver, HCC and matched paracancerous tissues of humans were compared using one-way ANOVA. The $x^{2}$-test was used to analyse the Ki67 rate differences among mouse normal liver tissues and paired paracancerous and HCC samples. Values of $P<0.05$ were considered statistically significant. All of the data analyses were performed using GraphPad Prism Version software, version 7.0, and SPSS software, version 22.0.

\section{Results}

Expression of NF-kB family members and phosphorylation of p65 in HCC patients

In recent years, the molecular mechanisms between inflammation and tumorigenesis have been largely evaluated. As a key regulator of inflammation and immune responses, the NF- $\kappa \mathrm{B}$ pathway can act as a promoter or tumour suppresser [23]. To assess the relationship between NF-kBp65 and human HCC, mRNA level results revealed that p65 was significantly upregulated in HCC compared with normal liver tissues and paracancerous tissues (Fig. 1a). Immunohistochemistry was performed to detect the protein levels of five cellular DNA-binding subunits of NF-kB in 6 normal liver tissues and matched HCC with adjacent paracancerous tissues. Significant differences in p65 expression among normal tissues, paracancerous tissues and HCC tissues were found.
Protein levels revealed that p65 was significantly upregulated in HCC compared with normal liver tissues and paracancerous tissues (Fig. 1b). Furthermore, the protein levels of the phosphorylated forms of five subunits of NF- $\kappa B$ were also detected by immunohistochemistry staining. Consistently, upregulated p-p65 expression levels were found in both paracancerous $(70.8 \%)$ and HCC tissues (62.5\%) compared with normal tissues (Fig. 1c, d). Arrested p-p65 staining, predominantly in the nucleus, and upregulated p-p65 expression at Ser536, Ser276 or Ser529 residues were observed in HCC liver tissues (Fig. 1c, e). We then examined the serum protein levels of p65 and p-p65 in 6 healthy volunteers and 6 HBV-infected HCC patients using western blotting. The results showed that p-p65 expression was significantly upregulated in the serum of HCC patients, which could be an effective biomarker of HCC patients (Fig. 1f, g). These results indicated that $\mathrm{p} 65$, as well as phosphorylation of p65, might play a critical role in inflammationrelated hepatocellular carcinogenesis. Previous studies have demonstrated that activation of the NF- $\mathrm{kB}$ pathway can promote $\mathrm{HCC}$ progression and that the classical NF-кB pathway mainly targets p50-p65 heterodimers. We then mainly focused on the clinical significance of p65 and p-p65 in HCC patients.

\section{Deficiency of hepatocyte p65 inhibited hepatocellular carcinogenesis and cancer growth in mice}

Our data showed that p65 expression was increased in HBV-infected HCC tissue in humans (Fig. 1). However, the relationship between p65 and hepatocarcinogenesis still requires further study. Here, to evaluate the effect of p65 on hepatocarcinogenesis, we established a hepatocyte-specific deletion of the RELA gene in mice by crossing floxed-p65 littermates $\left(\mathrm{p} 65^{\mathrm{f} / \mathrm{f}}\right)$ with Alb$\mathrm{cre}^{+/-}$mice, which consequentially lacked the expression of p65 and p-p65. A single intraperitoneal injection of DEN $(15 \mathrm{mg} / \mathrm{kg})$ in 14-day-old male mice led to effective HCC production. L-p65 knockout (KO) (p65 $5^{\mathrm{f} / \mathrm{f}}$, Alb$\left.\mathrm{cre}^{+/-}\right)$male mice and wild-type (WT) $\left(\mathrm{p} 65^{\mathrm{f} / \mathrm{f}}\right)$ male mice were treated with a single injection of DEN. Tumour incidence and size were compared 9 months after injection. Hepatocellular carcinomas developed in all mice. However, the hepatocellular carcinoma incidence was reduced in $L-p 65 \mathrm{KO}$ mice compared with WT mice (Fig. 2a, b). No significant difference was found in the serum AFP levels of WT and $L$-p $65 \mathrm{KO}$ mice since AFP is an early biomarker of HCC (Figure S1a). The percentage of liver weight versus body weight in $L-p 65 \mathrm{KO}$ mice was decreased by 1.6 fold compared with WT mice $(4.32 \pm 1.22$ vs. $7.14 \pm 2.69)$ (Figure S1b). The maximal tumour size and average tumour numbers were reduced significantly in $L-p 65 \mathrm{KO}$ mice compared with WT mice (Figure S1c, d). Histopathological analysis was used to 
a

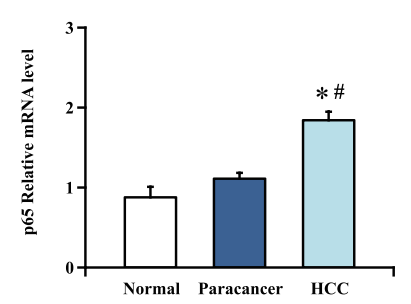

b

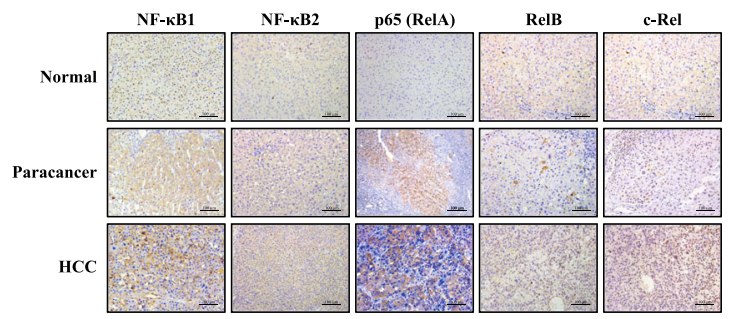

d

c

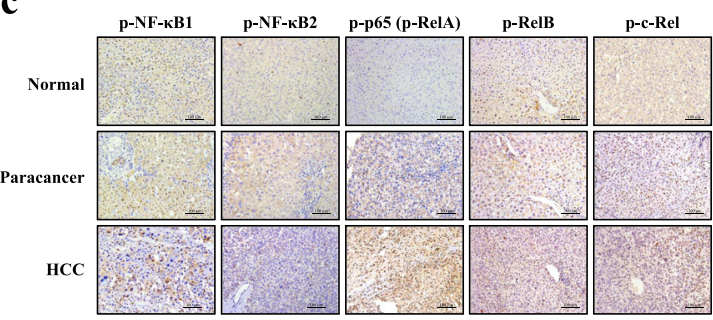

The expression of p-p65 in hepatocellular carcinogenesis

\begin{tabular}{cccc}
\hline p-p65 & $\begin{array}{c}\text { Normal } \\
(\mathrm{n}=6)\end{array}$ & $\begin{array}{c}\text { Paracancer } \\
(\mathrm{n}=24)\end{array}$ & $\begin{array}{c}\text { HCC } \\
(\mathrm{n}=24)\end{array}$ \\
\hline \multirow{2}{*}{ Weak } & 6 & 7 & 9 \\
& $(100.0 \%)$ & $(29.2 \%)$ & $(37.5 \%)$ \\
\multirow{2}{*}{ Strong } & 0 & 17 & 15 \\
& $(0.0 \%)$ & $(70.8 \%)$ & $(62.5 \%)$ \\
\hline
\end{tabular}

e

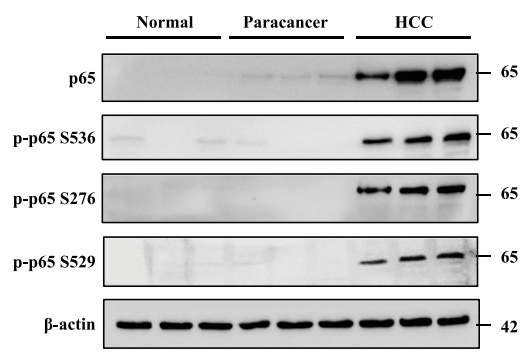

f

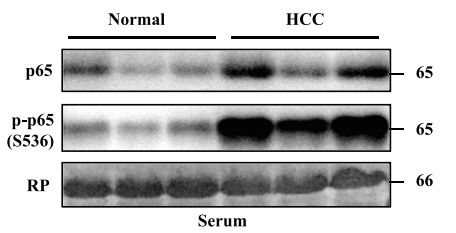

g

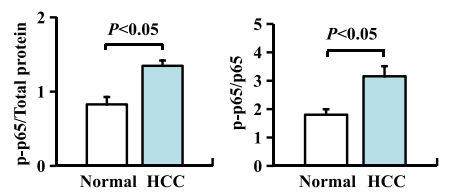

Fig. 1 Expression of NF-KB family members and phosphorylation of p65 in HCC patients. a p65 mRNA levels in normal human liver, HCC and paracancerous tissue were analysed by real-time PCR. Values are mean \pm s.d. ( $n=6$ for normal liver, $n=10$ for HCC and matched paracancerous tissues); ${ }^{*} P<0.05$ compared with normal liver tissues, ${ }^{\#} P<0.05$ compared with paracancerous tissues by one-way ANOVA. b Immunohistochemical analysis of NF-kB subunits from normal human liver, HCC and matched paracancerous tissues. c Immunohistochemical analysis of phospho-NF-kB subunits in normal human liver, HCC and matched paracancerous tissues. $\mathbf{d}$ Immunohistochemistry staining was performed to confirm the expression of p-p65 (p-RelA) in 6 normal liver tissue samples and 24 paired HCC samples with matched paracancerous tissues. e p65 and p65 S536, p65 S276, and p65 S529 protein expression levels in normal human liver tissue, HCC and paracancerous tissue using western blotting assay. $\mathbf{f}, \mathbf{g}$ p 65 and p-p65 protein expression in the blood serum of healthy volunteers and HCC patients. The bottom panel shows red Ponceau (RP) staining of the PVDF membrane after transfer as a control of loading. The position and size in kilodaltons of molecular mass markers are indicated on the right. Values are mean $\pm \mathrm{SD}(n=6$ in each group). $P<0.05$ using Student's $t$-test

confirm mouse hepatocellular cancer (Fig. 2c). Ki67 staining was performed to analyse the proliferation of liver tumours, showing that the number of Ki67-positive cells was reduced in $L$-p $65 \mathrm{KO}$ mice compared with WT mice (Fig. 2d). Furthermore, a tumorigenicity experiment in Balb/c nude mice showed that inhibition of p65 significantly reduced xenograft tumour growth in vivo (Fig. 2e-h). These results demonstrated that deficiency of p65 and p-p65 suppresses DEN-induced hepatocarcinogenesis by downregulating hepatic compensatory proliferation.

\section{Inflammation-induced NF-KBp65 phosphorylation is involved in hepatocellular carcinogenesis}

Our data showed that phosphorylation of p65 was increased in $\mathrm{HBV}$-infected $\mathrm{HCC}$ and adjacent tissues in humans. However, the role of p-p65 induced by inflammation in carcinogenesis in mice remains unclear. To determine the potential role of p65 phosphorylation in chemical tumorigenicity, we analysed mouse livers 9 months after DEN treatment. All male mice efficiently developed hepatocellular carcinoma by 9 months. Immunohistochemistry was used to determine the phosphop65 expression of liver tumour samples, and we found 


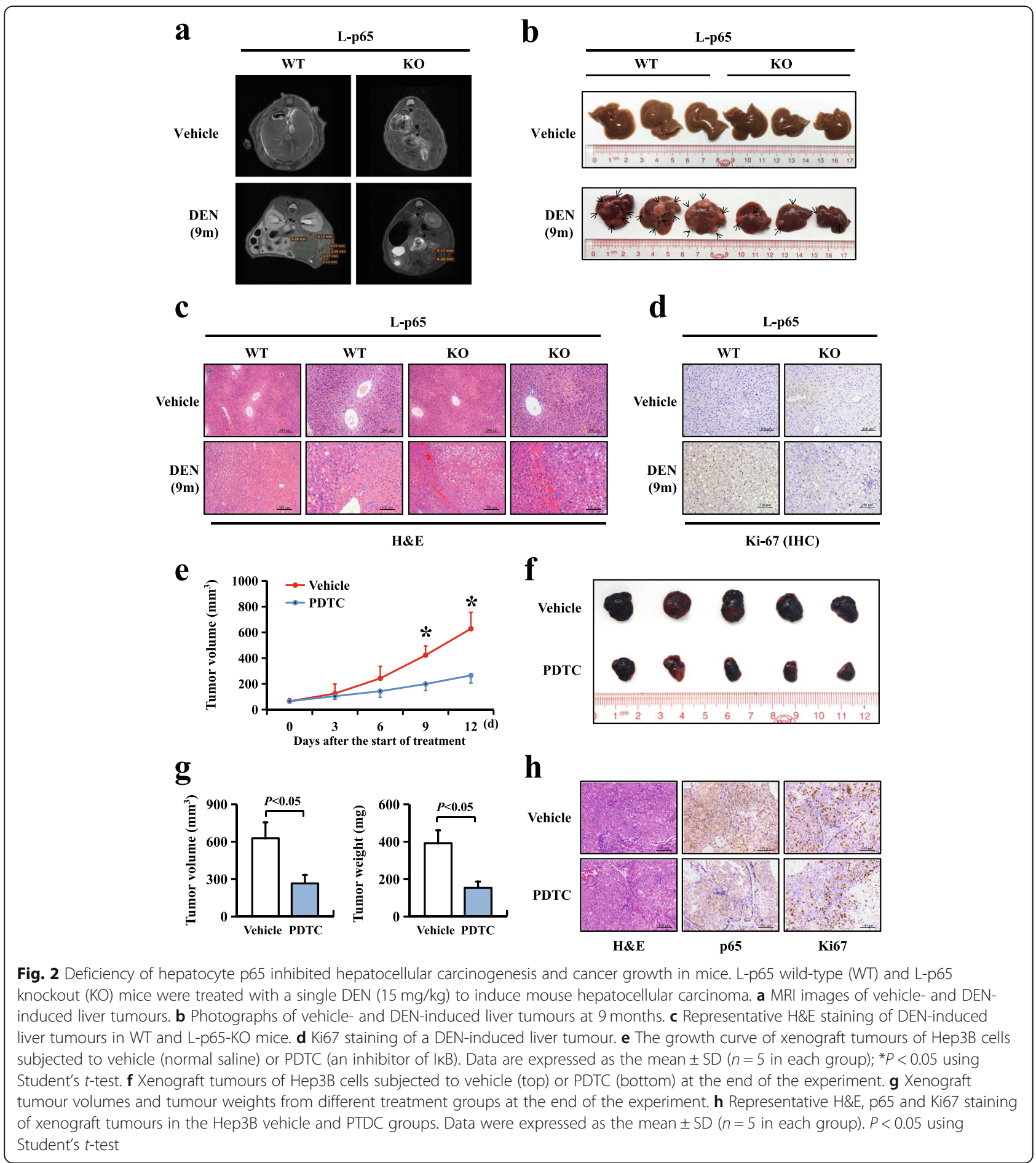

that p-p65 was remarkably assembled in the nuclei of hepatocytes (Fig. 3a), and the expression of p-p65 in mouse tumours was increased compared with that in control mouse livers using a western blotting assay (Fig. 3b). To further confirm the translocation of p65 in the DEN-induced HCC mouse model, nuclear and cytoplasmic fractions were isolated. Increased p65 nuclear translocation in DEN-induced mouse HCC models was observed (Fig. 3c). The analyses of tumour cell proliferation were confirmed by Ki67 staining and immunoblotting of PCNA (Figure S2a, b). The Ki67 index and PCNA index showed that cell proliferation was increased 

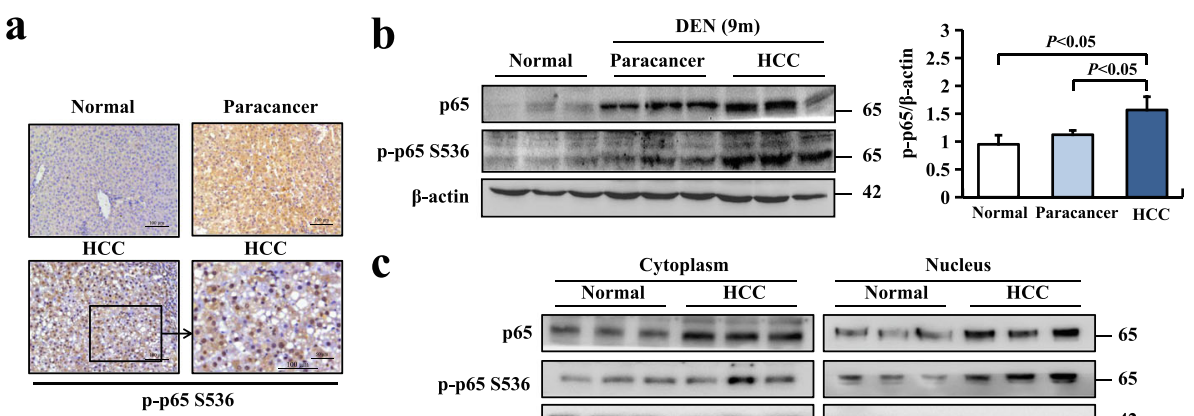

c
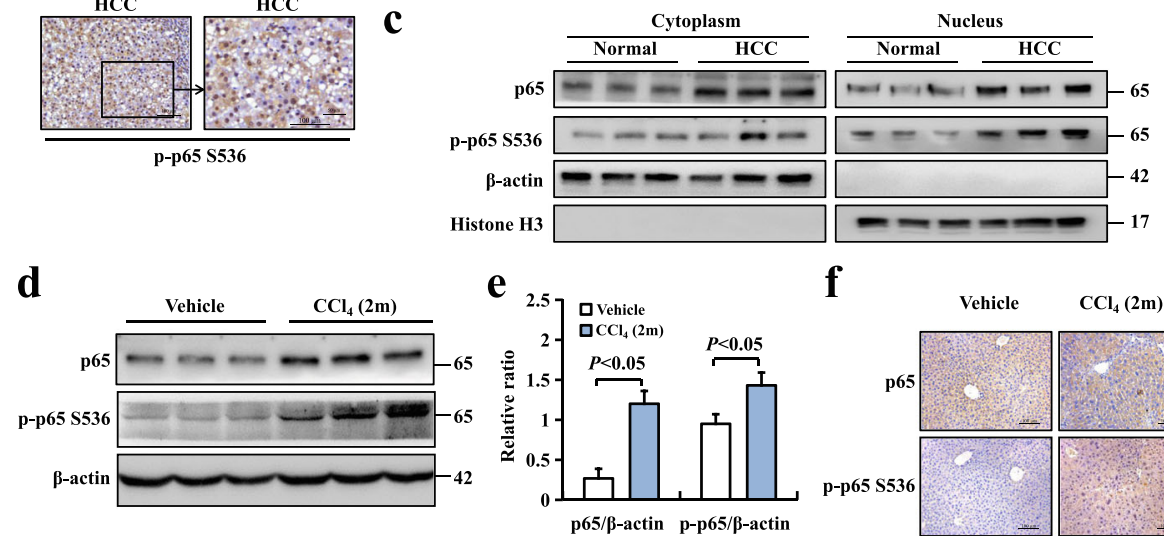

f
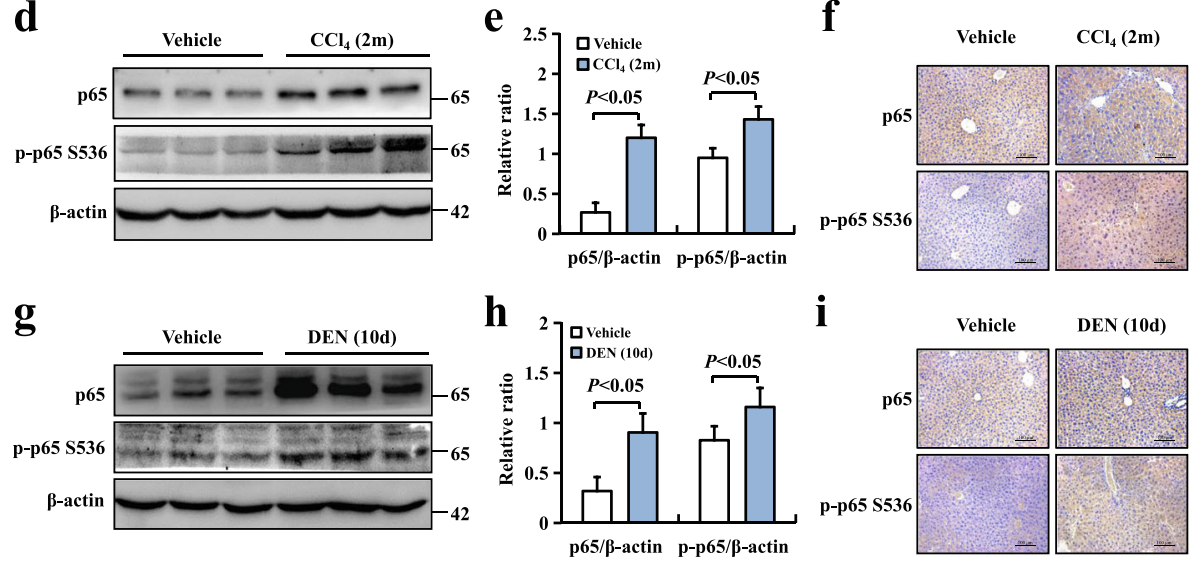

i
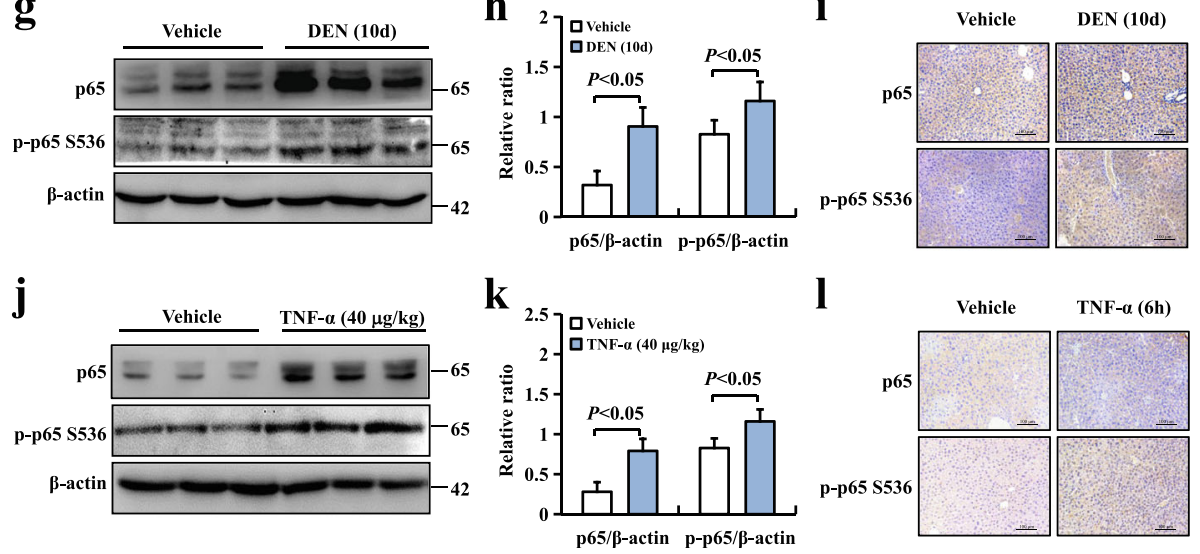

Fig. 3 Inflammation-induced NF-kBp65 phosphorylation is involved in hepatocellular carcinogenesis. DEN-induced mouse hepatocellular carcinomas were intraperitoneally injected after either physiological saline (vehicle) or a single DEN (15 mg/kg), and the mouse livers were harvested at 9 months after injection. Normal liver tissues were obtained from vehicle mouse livers, HCC tissues from 9-month DEN-induced mouse liver tumours and paracancerous tissues from adjacent noncancerous tissues. a Representative images of p-p65 staining in DEN-induced mouse HCC models. b p65 and p-p65 protein expressions in mouse livers were determined using western blotting. c p65 was analysed in the nuclear and cytoplasmic fractions of normal liver cells isolated from normal control mice and liver tumour cells isolated 9 months after DEN injection. $\beta$-actin and histone $\mathrm{H} 3$ were used as the controls for loading and fractionation. $\mathbf{d}$, e p65 and p-p65 protein expressions in mouse livers were determined by western blotting after either physiological saline (vehicle) or tetrachloromethane $\left(\mathrm{CCl}_{4}\right)(15 \mathrm{mg} / \mathrm{kg})$ intraperitoneal injection

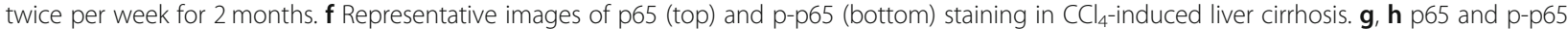
protein expressions in mouse livers after either physiological saline (vehicle) or $100 \mathrm{mg} / \mathrm{kg}$ diethylnitrosamine (DEN) intraperitoneal injection for 10 days were determined using western blotting. i Representative images of p65 (top) and p-p65 (bottom) staining in DEN-induced liver inflammation. j, k p65 and p-p65 protein expressions in mouse livers were determined using western blotting after intraperitoneal TNF-a $(40 \mu \mathrm{g} /$ $\mathrm{kg}$ ) injection for $6 \mathrm{~h}$. I Representative images of p65 (top) and p-p65 (bottom) staining in TNF-a-induced liver inflammation. Values are mean \pm SD ( $n=6$ in each group). $P<0.05$ using Student's $t$-test

in HCC (Figure S2c). Previous data have shown that NF$\kappa$ Bp65-driven inflammation is closely related to hepatocellular carcinoma (HCC), but evidence has shown a doubled-edged effect among numerous mouse models.

We then established several acute inflammation mouse models by tetrachloromethane $\left(\mathrm{CCl}_{4}\right.$, a drug with marked hepatotoxicity), diethylnitrosamine (DEN, a drug that promotes hepatocarcinogenesis by DNA damage) and TNF- $\alpha$ (a potent activator of NF-kB) [10]. Western blotting showed that the protein levels of both p65 and p-p65 were significantly increased in liver tissues after intraperitoneal injection of $\mathrm{CCl}_{4}$ for 2 months (Fig. 3d, 
e), DEN for 10 days (Fig. 3g, h) and TNF- $\alpha$ for $6 \mathrm{~h}$ (Fig. 3 j, k). Moreover, real-time PCR analysis was performed to measure the mRNA levels of $p 65$ and TNF- $\alpha$ in the aforementioned acute inflammatory mouse models, and elevated $p 65$ and TNF- $\alpha$ mRNA levels were observed (Figure S3). Simultaneously, p-p65 levels were apparently upregulated in the nuclei of hepatocytes after $\mathrm{CCl}_{4}$ (Fig. 3f), DEN (Fig. 3i) and TNF- $\alpha$ treatment (Fig. 3l), as determined by immunohistochemistry, indicating increased translocation of p65 into the nucleus. These data suggested that p65 is activated and that the translocation of phosphorylated p65 into the nucleus is markedly increased by $\mathrm{CCl}_{4^{-}}, \mathrm{DEN}-$ or TNF- $\alpha$-induced hepatic inflammation.

\section{Inhibiting NF-KBp65 phosphorylation depressed hepatocellular proliferation}

The negative effect of p-p65 deficiency on DEN-induced hepatocarcinogenesis was caused by downregulating proliferation in mice. However, the role of p-p65 in the malignant phenotype of $\mathrm{HCC}$ cell lines awaits further study. To evaluate the effect of p-p65, HCC cell lines, including LO2, HepG2, HepG2.2.15 and Hep3B cells, were treated with Bay 11-7082 (an inhibitor of IкB) (Fig. 4a). Bay 11-7082 inhibited cell growth and colony formation (Fig. 4b) among the four HCC cell lines after treatment (Fig. 4c-f). These data indicated that the inhibition of p65 phosphorylation depressed hepatocellular proliferation in human HCC cell lines.

Phosphorylation of NF-KBp65 Ser536, but not Ser276 and Ser529, was upregulated by inflammation-mediated ARRB1

Our previous study showed that inflammatory TNF- $\alpha$ directly increases hepatic ARRB1 expression, resulting in malignant hepatocellular proliferation and carcinogenesis. Spontaneously, the relationship between ARRB1 and p65 in inflammation-induced hepatocarcinogenesis aroused our interest. To determine the critical residues of p-p65 in ARRB1-mediated hepatocellular carcinogenesis, ARRB1 expression was upregulated in HepG2 and Hep3B cells by a recombinant lentivirus expressing ARRB1. We found that p65 Ser536, but not Ser276 or Ser529, was markedly phosphorylated after ARRB1 overexpression in HepG2 and Hep3B cells (Fig. 5a). These results indicated that Ser536 was the critical residue of p-p65 in ARRB1-mediated hepatocellular carcinoma. To evaluate whether ARRB1 had any effect on p65 Ser536 in HCC cells, ARRB1 expression was upregulated in LO2, HepG2, HepG2.2.15 and Hep3B cells by a recombinant lentivirus expressing ARRB1 (Fig. 5b). We found that p65 Ser536 was markedly phosphorylated, while the total amounts of p65 remained the same as those in control cells (Fig. 5c, d). In response to a range of stimuli, phosphorylated cytoplasmic p65 relocates to the nucleus and promotes the activation of a series of target genes. An increase in the fluorescence intensity of p65 in the nucleus was confirmed using immunofluorescence (Fig. 5e). To further confirm that ARRB1 facilitates p65 translocation into the nucleus, nuclear and cytoplasmic fractions were isolated and examined from LO2, HepG2, and Hep3B cell line samples after ARRB1 transfection. The results showed increased p65 nuclear translocation after ARRB1 transfection (Fig. 5f). We then treated three HCC cell lines with TNF- $\alpha(40 \mathrm{ng} / \mathrm{ml})$, and markedly increased ARRB1 expression was observed, as confirmed by our previous study [16], while p-p65 levels were found to be elevated in HCC cell lines compared with the control TNF- $\alpha$-treated cells (Fig. $5 \mathrm{~g}, \mathrm{~h}$ ). These results indicated that the phosphorylation of p 65 could be upregulated by the inflammation-mediated ARRB1 pathway in vitro.

\section{Phosphorylation of NF-kBp65 enhanced hepatocellular proliferation through the Akt/mTOR pathway in response to inflammation}

Accumulating evidence has found that the Akt/GSK3 $\beta$ pathway can accelerate cell cycle progression in various types of tumours, and a previous study reported that Akt signalling could promote survival or inhibit apoptosis through substrates mediated in proportion by NF$\kappa B$ [24]. It remains unknown whether the Akt/GSK3 $\beta$ signalling pathway is related to the phosphorylation of p65 during HCC cell proliferation. To explore the possible mechanism of p-p65 in hepatocarcinogenesis, we treated WT mice with TNF- $\alpha(40 \mu \mathrm{g} / \mathrm{kg})$ and found significantly increased protein levels of p-p65, p-Akt, PCNA and downstream components of Akt, including p-GSK3 $\beta$ and $\mathrm{m}$-TOR, in mouse livers using western blotting and obviously increased expression of p-p65 and PCNA using immunohistochemistry (Fig. 6a-c). We also observed that pretreatment with TNF- $\alpha(40 \mathrm{ng} / \mathrm{ml})$ for $6 \mathrm{~h}$ promoted the expression of ARRB1 and p-p65 in HCC cell lines and found that p-Akt, p-GSK3 $\beta$, pmTOR and PCNA were markedly increased, consistent with the data obtained from WT mice. HCC cell proliferation was confirmed to be upregulated after TNF- $\alpha$ pretreatment of HepG2 cells, represented by double staining of p-p65 and EdU (Fig. 6d-f). Altogether, these results suggested that phosphorylation of NF-kBp65 enhanced hepatocellular proliferation through the GSK3 $\beta$ / mTOR pathway.

\section{Phosphorylation of NF-KBp65 induced GSK3 $3 / \mathrm{mTOR}$ signalling in an ARRB1-dependent manner}

Although previous results have suggested that ARRB1 can promote the phosphorylation of p65 in vivo and that phosphorylation of p65 promotes HCC cell proliferation 


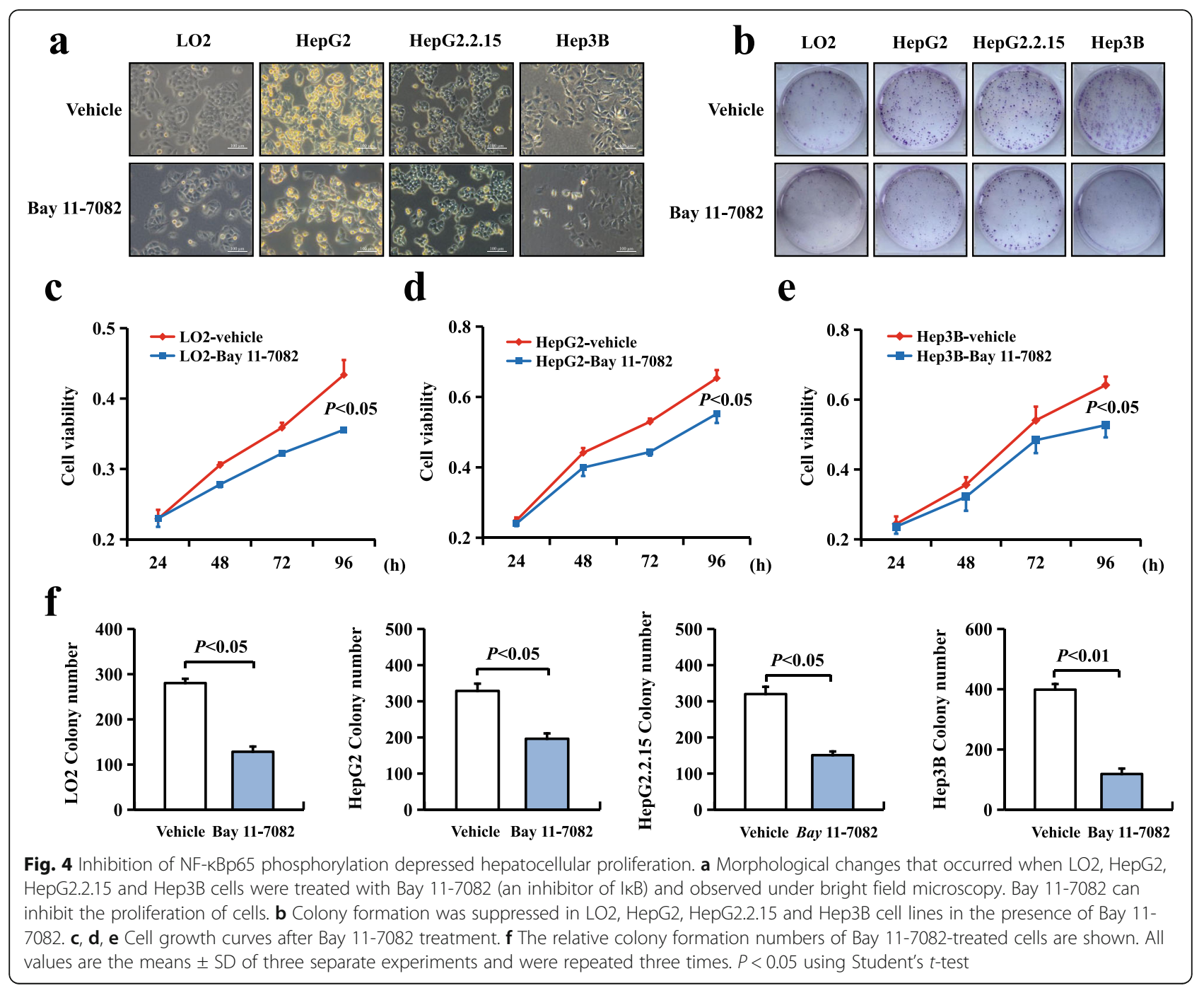

through the GSK3 $\beta / \mathrm{mTOR}$ pathway, it remains unknown whether the p65/GSK3 $\beta / \mathrm{mTOR}$ signalling pathway is ARRB1 dependent in DEN-induced hepatocellular carcinogenesis. We evaluated Akt, p65 and GSK3 $\beta$ phosphorylation in both ARRB1 WT and ARRB1 KO mice after DEN treatment for 10 days. ARRB1 deficiency significantly weakened DEN-induced Akt, p65, GSK3 $3, \mathrm{~m}$-TOR phosphorylation and PCNA expression (Fig. 7a). We then examined Akt and GSK3 $\beta$ phosphorylation in both WT and $L-p 65 \mathrm{KO}$ mice after DEN treatment for 10 days, and our data showed that p65 deficiency significantly weakened DEN-induced GSK3 $\beta, \mathrm{m}$-TOR phosphorylation and PCNA expression but did not affect the phosphorylation of Akt (Fig. 7b) or increase the expression of p-GSK3 $\beta$ and PCNA using immunohistochemistry (Fig. 7c). The preceding results suggested that ARRB1 enhanced the phosphorylation of p65 and induced hepatocellular proliferation, but whether ARRB1 and p65 directly interact (including pp65) remains unclear. We then performed a coimmunoprecipitation assay in ARRB1-overexpressing HepG2 cells and found that both p-p65 and p65 could directly bind to ARRB1 (Fig. 7d). Furthermore, TNF- $\alpha$ significantly increased the interaction of ARRB1 with p65 and p-p65 (Fig. 7e). Considered together, our results indicated that phosphorylation of NF-KBp65 induced hepatocellular carcinogenesis through ARRB1-dependent GSK3 $\beta / \mathrm{mTOR}$ signalling.

\section{Akt/mTOR signalling, and the ARRB1 promoter were} activated through NF-KBp65 phosphorylation on Ser536 Our data proved that Ser536 was the critical residue of p-p65 in ARRB1-mediated hepatocellular carcinogenesis (Fig. 5a). Herein, we overexpressed normal active (WT), constitutively inactive (Ser536A), and constitutively active (Ser536E) NF-kBp65 in HepG2 and Hep3B cells. 
$\mathbf{a}$

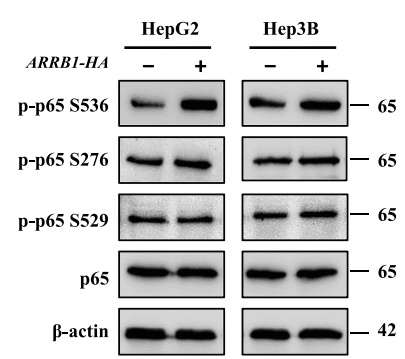

c
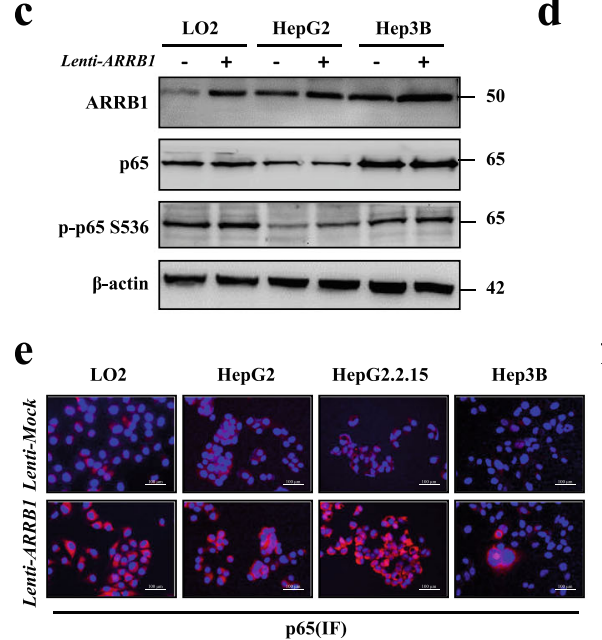

g

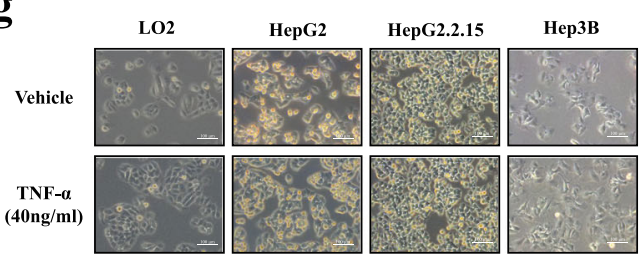

b

d

f
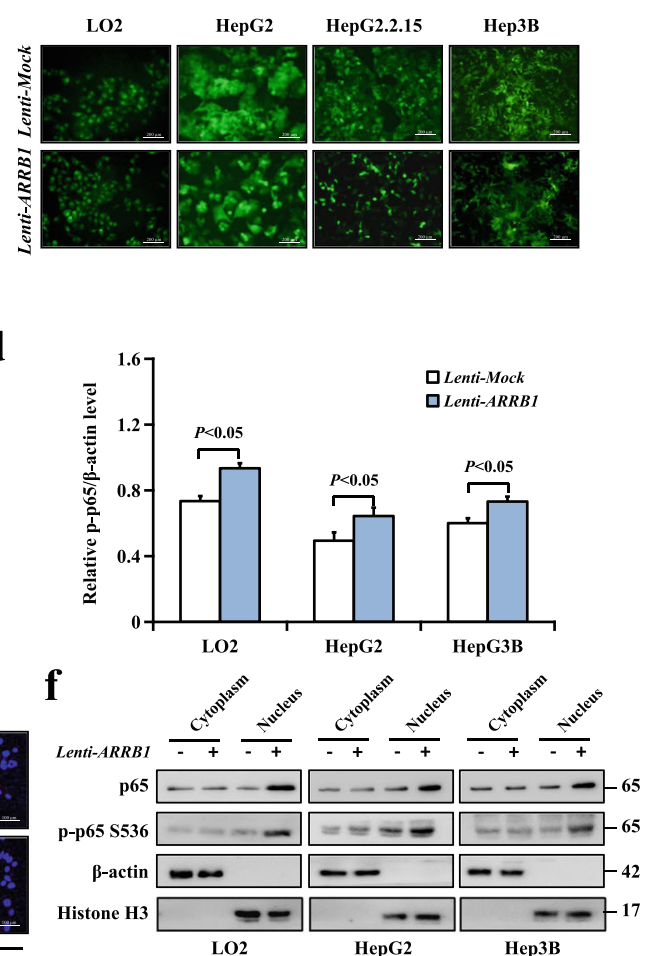

h

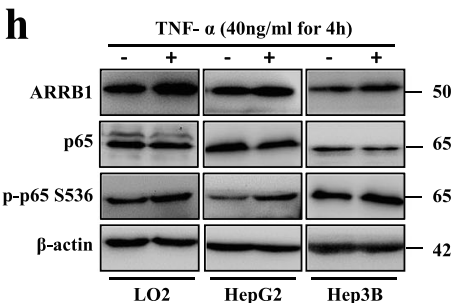

Fig. 5 Phosphorylation of NF-kBp65 Ser536, but not Ser276 and Ser529, was upregulated by inflammation-mediated ARRB1. a ARRB1 transfection increased the expression of p65 Ser536, but not p65 Ser276 and Ser529, in HepG2 and HepG3B cell lines. b Cells were infected with ARRB1 or control lentivirus in LO2, HepG2, HepG2.2.15, and Hep3B cell lines. Cells stably expressed ARBB1 after transfection and selection by puromycin. c, d ARRB1 transfection increased the expression of p-p65, but not p65, in LO2, HepG2 and Hep3B cell lines. e Fluorescence images showed induced nuclear p65 expression in LO2, HepG2, HepG2.2.15, and Hep3B cell lines following transfection of ARRB1 using the immunofluorescence assay. $\mathbf{f}$ p65 was analysed by western blotting in the nuclear and cytoplasmic fractions isolated from LO2, HepG2, and Hep3B cell line samples. $\beta$ actin and histone $\mathrm{H} 3$ were used as the controls for loading and fractionation. g Morphological changes that occurred when LO2, HepG2, HepG2.2.15, and Hep3B cells were treated with TNF-a (40 ng/ml) for $4 \mathrm{~h}$ and observed under bright field microscopy. $\mathbf{h}$ LO2, HepG2 and Hep3B cells were treated with TNF- $a(40 \mathrm{ng} / \mathrm{ml})$ for $4 \mathrm{~h}$, and the expression of ARRB1, p65 and p-p65 was analysed using western blotting. All values are the means $\pm \mathrm{SD}$ of three separate experiments and were repeated three times. $P<0.01$ or $P<0.05$ using Student's $t$-test

We found significantly increased levels of p-p65, p-Akt, $\mathrm{p}$-GSK3 3 , and especial the p-m-TOR level, in active p65 Ser536E cells and, conversely, less increased levels of $\mathrm{p}-$ p65, p-Akt, p-GSK3 $\beta$ and p-m-TOR in inactive p65 Ser536A cells (Fig. 8a-d). Considering that both p65 and ARRB1 were upregulated in HCC, we further examined the activity of the $p 65$ promoter and ARRB1 promoter after overexpressing normal active (WT), constitutively inactive (Ser536A), and constitutively active (Ser536E) NF-kBp65 in $293 \mathrm{~T}$ cells. Increased activities of the $A R R B 1$ promoter, but not the $p 65$ promoter, was observed in active p65 Ser536E cells, while conversely, less increased activities of the ARRB1 promoter was observed in inactive p65 Ser536A cells (Fig. 8e). Altogether, we confirmed that inflammation mediated hepatocellular carcinogenesis through phosphorylation of NF- $\mathrm{kBp} 65$ on Ser536.

\section{Discussion}

A number of studies have examined the molecular mechanisms that connect inflammation to tumorigenesis, and NF- $\mathrm{kB}$ is a group of transcription factors that 


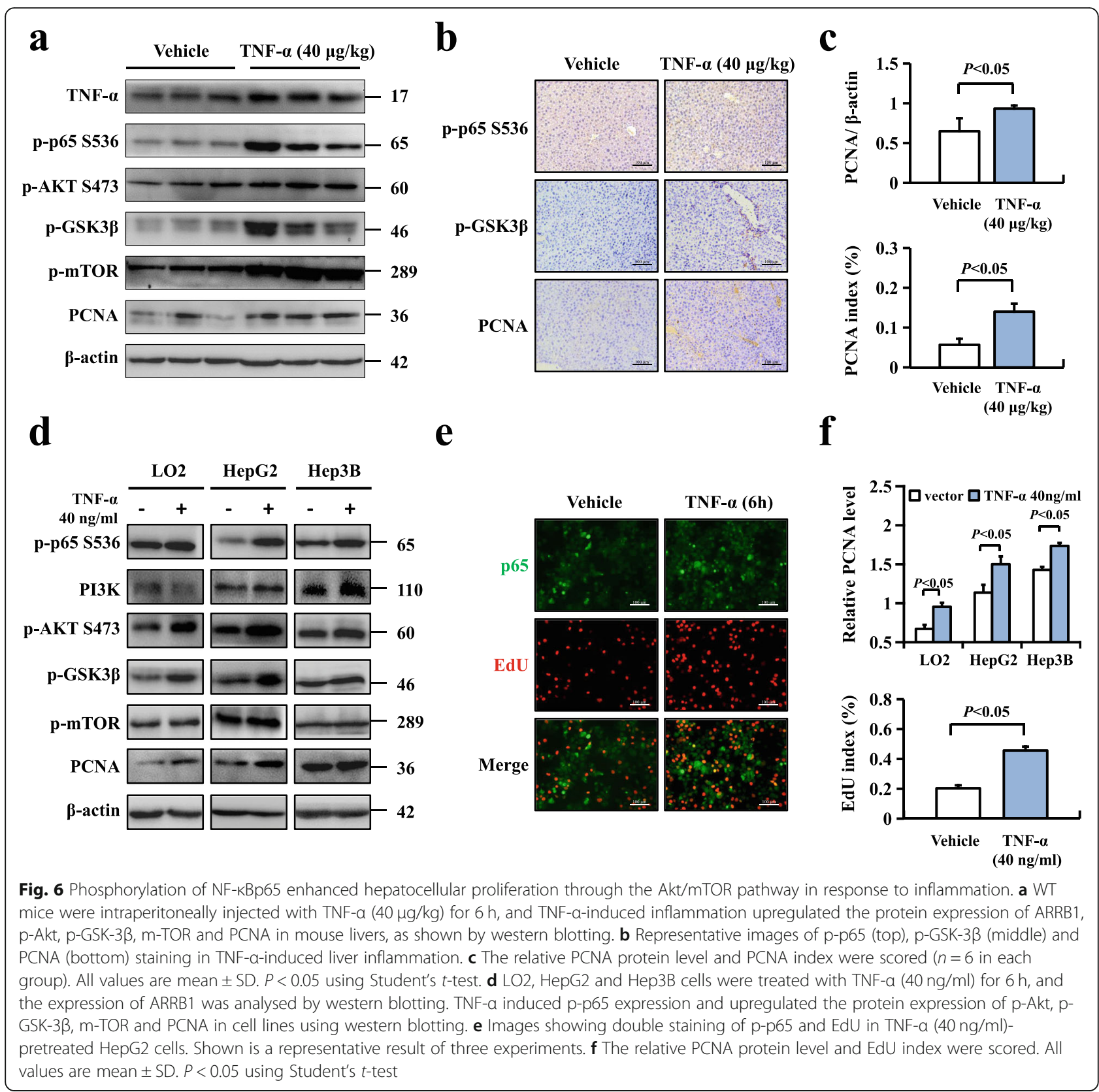

play central roles in inflammation. ARRB1 can promote HCC cell proliferation through the PI3K/Akt pathway and function as an enhancer of the GPCR-stimulated NF- $\kappa B$ pathway. Considering that NF- $\kappa$ Bp 65 was found to be related to the progression of $\mathrm{HCC}$, we revealed that p65 and phosphorylation of p65 are upregulated in HCC patients and essential to mouse acute hepatitis and liver cancer. Our data suggested that inflammation induced proinflammatory cytokines and enhanced the expression of ARRB1, which activated the phosphorylation of NF-кBp65, resulting in hepatocarcinogenesis by hepatocellular compensatory proliferation $[25,26]$.
This observation is consistent with the earliest report of NF- $\mathrm{kB}$ in carcinogenesis by multidrug resistance protein 2 (MDR2) deficient $\left(\mathrm{Mdr}^{-/-}\right)$mice, which were found to spontaneously develop cholestatic hepatitis and HCC. The inhibition of NF-kB in $\mathrm{Mdr}^{-/-}$mice, obtained from the introduction of nondegradable IкB, blocked the progression of hepatocellular carcinoma by hepatocyte apoptosis [27]. Another study deleted IKK $\beta$ in intestinal epithelial cells and found a significant decrease in tumour incidence [8]. The $\operatorname{IKK} \beta(\mathrm{EE})^{\mathrm{Hep}}$ model, with constitutive IKK activation, showed apparent ectopic lymphoid-like structures (ELSs), which 
a
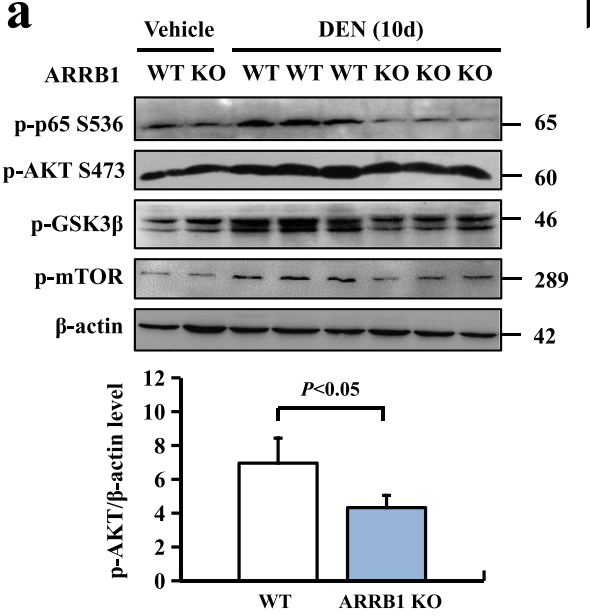

c

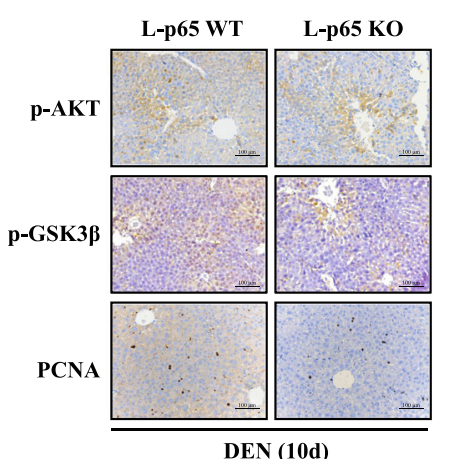

d b
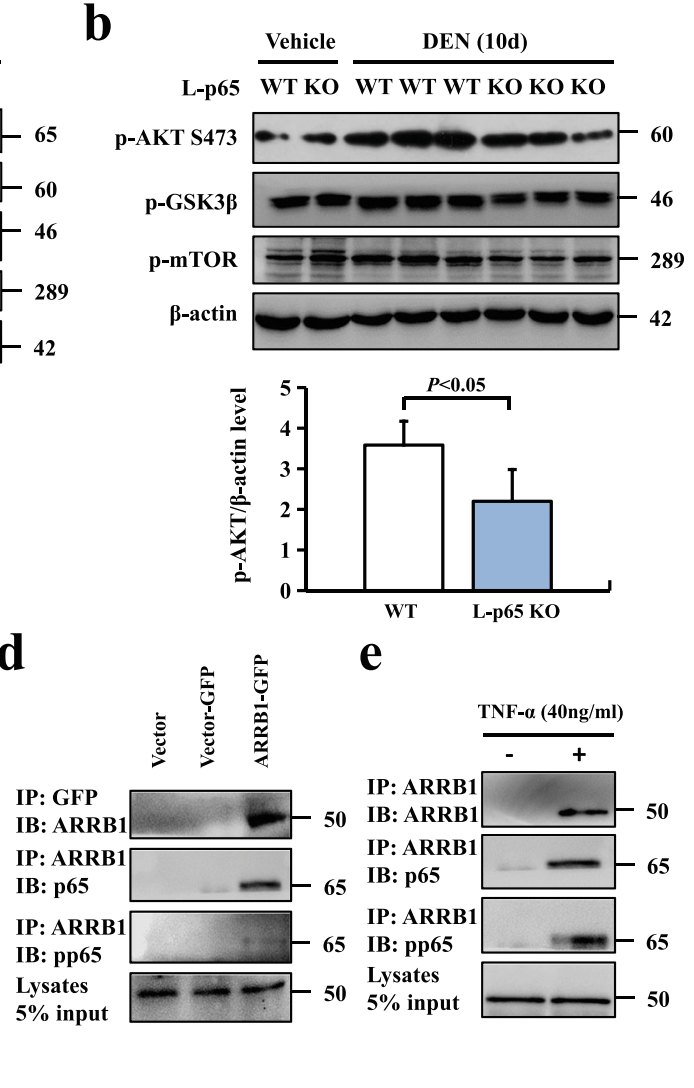

Fig. 7 Phosphorylation of NF-KBp65 induced Akt/mTOR signalling in an ARRB1-dependent manner. $\mathbf{a}, \mathbf{b} L-p 65$ KO mice and ARRB1-KO mice were treated with either physiological saline (vehicle) or $100 \mathrm{mg} / \mathrm{kg}$ DEN intraperitoneal injection for 10 days. The protein levels of ARRB1, p-p65, p-Akt p-GSK-3 and m-TOR. Relative p-p65 level was scored ( $n=6$ in each group). All values are mean \pm SD. $P<0.05$ using Student's $t$-test. ( $n=6$ in each group). c Representative images of p-p65 (top), p-GSK3 3 (middle) and PCNA (bottom) staining in DEN-induced L-p65 KO mouse liver inflammation. d ARRB1-overexpressing cells were established as described. The cellular lysates of ARRB1-transfected HepG2 cells were subjected to immunoprecipitation with an anti-GFP antibody. Coimmunoprecipitated endogenous p65 and p-p65 were detected. e TNF-a (40 ng/ml)treated HepG2 cell lysates were subjected to immunoprecipitation with an anti-ARRB1 antibody. Coimmunoprecipitated endogenous p65 and pp65 were detected with anti-p65 or p-p65 antibodies. Shown is a representative result of three experiments.

IP = immunoprecipitated; IB = immunoblot

promoted the progression of hepatocarcinogenesis both spontaneously and through DEN treatment through a mechanism that provided crucial survival and growth factors from the immune microniche environment [28]. In contrast, subsequent studies suggested that IKK $\beta$ deficient mice had markedly increased hepatocarcinogenesis after DEN treatment by compensatory proliferation, and hepatocyte-specific ablation of IKK $\gamma / \mathrm{NEMO}$ mice was found to spontaneously result in steatohepatitis followed by hepatocellular carcinoma $[26,29,30]$. However, a previous study determined the different responses to TNF treatment in hepatocyte-deficient IKK $\beta$ mice and hepatocyte RelA/p65-deficient mice caused by residual NF- $\mathrm{KB}$ activity [31]. IKK $\beta$-deficient hepatocytes were mildly sensitive to TNF-induced apoptosis, but RelA/p65-deficient hepatocytes were highly sensitive to TNF treatment. In this context, mice with conditional ablation of RelA/p65, IKK $\alpha / \mathrm{IKK} \beta$ or IKK $\gamma / \mathrm{NEMO}$ efficiently inhibited the NF- $\mathrm{kB}$ pathway but exhibited different hepatic phenotypes after treatment with TNF. More recent results have found that the controversy might be caused by NF-kB-independent functions $[6,23,32]$. A follow-up study suggested that IKK $\alpha / \mathrm{IKK} \beta$-dependent phosphorylation of receptorinteracting kinases (RIPKs) decreased the promotion of spontaneous liver tumours by inhibiting hepatocyte compensatory proliferation [33]. Furthermore, obesity and insulin resistance increased the risk of liver cancers, and our previous study suggested that inactivation of $\mathrm{p} 65$ in mouse livers improved insulin sensitivity through the cAMP/PKA pathway [21, 34]. Together, these results were consistent with our results and confirmed the decreased tumour incidence after DEN treatment in L-p65-KO mice. 


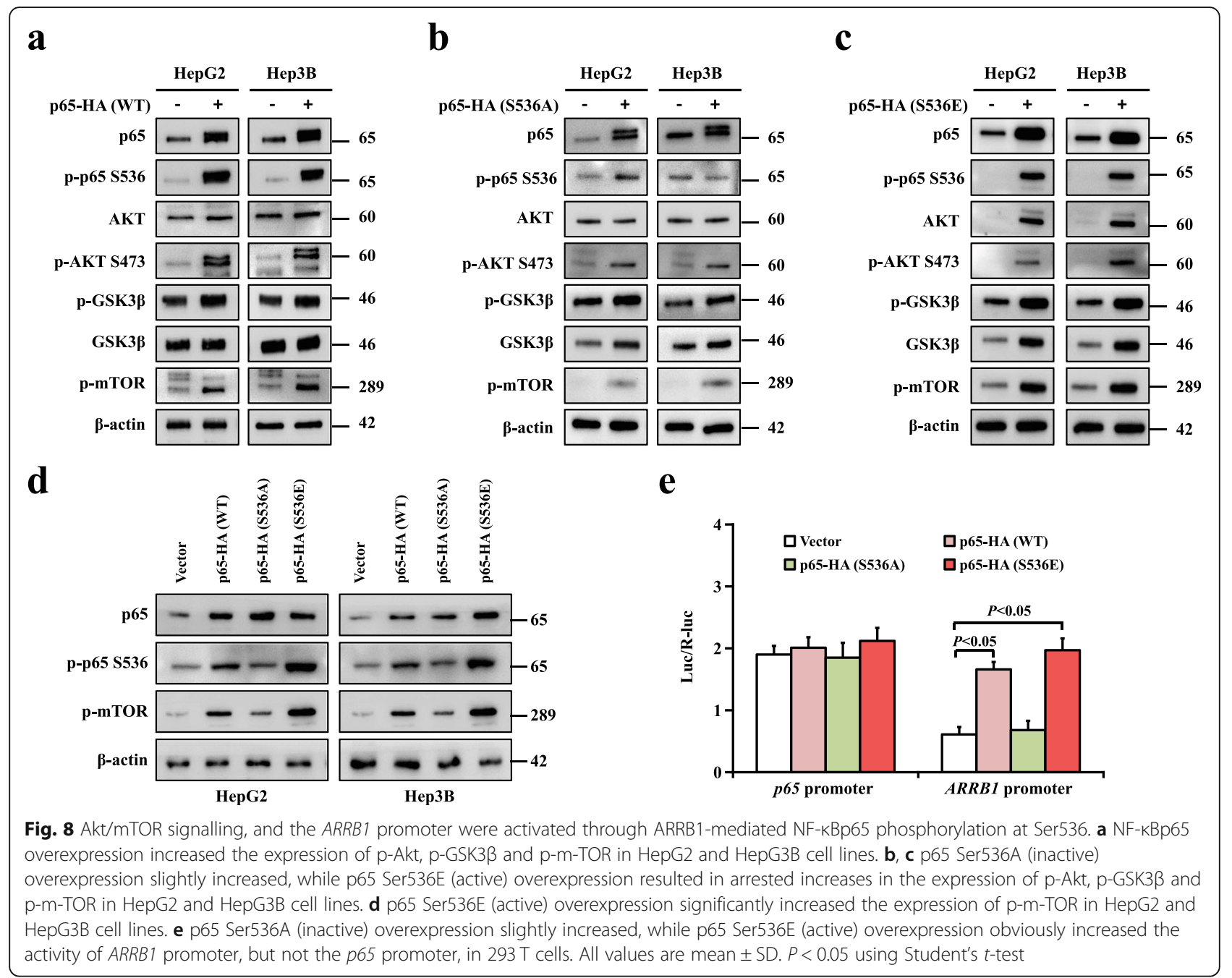

PI3K/Akt not only leads to the activation of both GSK3 $\beta$ and mTOR but also has been found upstream of NF- $\kappa B$ activation in different cancers, and the NF- $\mathrm{BB}$ pathway is believed to be a target of Akt [24, 35, 36]. Here, we identified that phosphorylation of p65 enhanced hepatocarcinogenesis through the GSK-3 $\beta /$ mTOR pathway. A recent study confirmed our results and suggested that inhibition of GSK3 $\beta$ decreased pmTOR levels and downstream molecules, which were related to cell survival and growth in HCC cells and inhibited tumour growth in vivo [20].

Previous studies have found that ARRB1 enhances hepatocarcinogenesis by inflammation-mediated signalling but inhibits the activation of NF-kB $[16,37]$. However, a recent view of the GPCR field has demonstrated that GPCR signalling can be directly transduced through ARRB1 and that the translocation of ARRB1 to the nucleus enhances NF- $\mathrm{kB}$ activity [38-40], consistent with our findings that overexpression of ARRB1 in HCC cell lines increases the level of p65 phosphorylation and promotes p65 translocation into the nucleus. Phosphorylation of p65 at Ser536 plays a vital role in hepatocellular carcinogenesis [41]. In this study, our results showed that ARRB1 significantly induces the phosphorylation of p65 Ser536 in human HCC cell lines and that phosphorylation of p65 Ser536 is involved in ARRB1-mediated hepatocarcinogenesis.

Other studies have shown that ARRB1 regulates several cancer-related cellular processes via diverse signal transduction pathways, including the Ras/Raf/MEK/ERK family, $\beta$-catenin/TCF4 signalling, Akt/GSK3 $\beta$ signalling, mTOR signalling and NF- $\mathrm{kB}$ signalling [38]. We then investigated the downstream molecular mechanisms of ARRB1-induced NF-kBp65 activation in hepatocellular carcinogenesis. The results showed that ARRB1 could interact with p65 Ser536, and the interaction was promoted after TNF- $\alpha$ treatment. The activities of Akt/ mTOR signalling, the ARRB1 promoter was NF-kBp65 Ser536 dependent, confirming the important role of ARRB1 in the NF-kBp65 Ser536 pathway. 


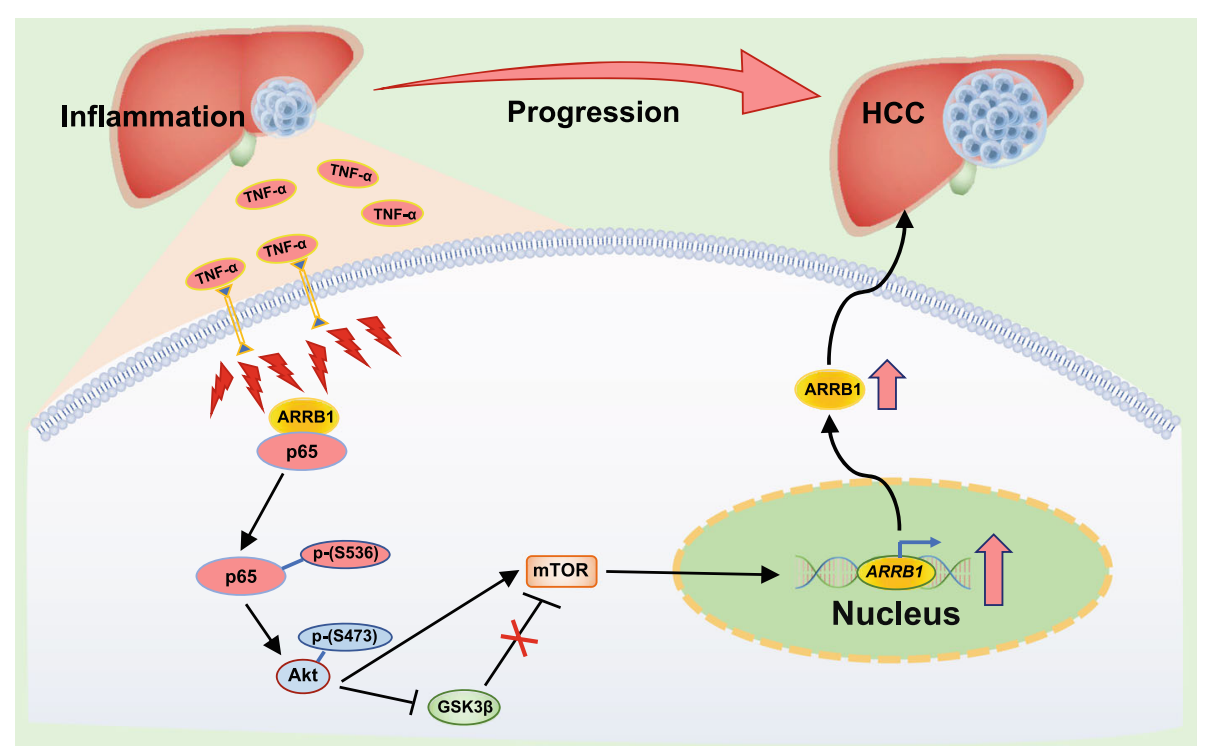

Fig. 9 Diagram of the mechanism by which NF-KBp65 phosphorylation drives hepatocellular carcinogenesis. Inflammation, such as TNF-a, induces ARRB1 and promotes ARRB1 binding to NF-KBp65, facilitating the phosphorylation of p65 at ser536. Then, the phosphorylation of p65 (Ser536) activates Akt/mTOR signalling to drive malignant hepatocellular proliferation, resulting in hepatocellular carcinogenesis

\section{Conclusions}

In conclusion, ARRB1 induced hepatocellular carcinogenesis via interaction with p65 to promote malignant hepatocellular proliferation through the GSK3 $\beta / \mathrm{mTOR}$ pathway (Fig. 9). Thus, inhibition of phosphorylation of NF-kBp65 at Ser536 has therapeutic benefits, and be targets of new pharmacotherapies for HCC patients.

\section{Abbreviations}

NF-kB: Nuclear factorkB; ARRB1: $\beta$-arrestin1; HCC: Hepatocellular carcinoma; EMT: Epithelial-mesenchymal transition; GPCRs: G protein-coupled receptors; TNF: Tumour necrosis factor; RHD: Rel homology domain; WT: Wild type; DEN: Diethylnitrosamine; $\mathrm{CCl}_{4}$ : Carbon tetrachloride; NLS: Nuclear localization signal; RIPKs: Receptor-interacting kinases; MDR2: Multidrug resistance protein 2; ELSs: Ectopic lymphoid-like structures

\section{Supplementary Information}

The online version contains supplementary material available at https://doi. org/10.1186/s13046-021-02062-x.

Additional file 1: Figure S1. Deficiency of hepatocytes p65 attenuated hepatocellular carcinogenesis in mice. (a) AFP levels of WT and L-p65-KO mice. (b) Quantification of average liver weight versus body weight in WT and L-p65-KO mice. (c) Maximal size of liver tumors measured by a caliper. (d) Average tumor numbers at 9 months. All values are mean \pm SD ( $n=10$ for each group). $P<0.05$ by using Student's $t$-test.

Additional file 2: Figure S2. Cell proliferation was increased in DENinduced HCC mouse model. (a) Representative images of ki67 staining in DEN-induced HCC. (b) PCNA expression in mice liver was determined by western blotting. (c) Ki67 index and PCNA relative protein level was scored. All values are mean \pm SD ( $n=6$ in each group). $P<0.05$ by using Student's t-test.

Additional file 3: Figure S3. The mRNA levels of $p 65$ and TNF- $a$ in the acute inflammatory mouse models were measured by Real time-PCR. (a) The mRNA level of p65 was elevated in liver tissues after intraperitoneal injection of $\mathrm{CCl}_{4}$ for 2 months, DEN for 10 days, or TNF-a $(40 \mu \mathrm{g} / \mathrm{kg})$ for 6 h. (b) The TNF-a mRNA level was elevated in liver tissues after intraperitoneal injection of $\mathrm{CCl}_{4}$ for 2 months, DEN for 10 days, or TNF-a $(40 \mu \mathrm{g} / \mathrm{kg})$ for $6 \mathrm{~h}$. All values are mean \pm SD ( $n=6$ in each group). $P<0.05$ by using Student's $t$-test.

\section{Acknowledgements}

The authors would like to thank Professor Jianping Ye of the Louisiana State University System for providing the floxed-p65 littermates $\left(p 65^{\mathrm{f} / \mathrm{f}}\right)$ mice and Alb-cre $^{+/-}$mice.

\section{Authors' contributions}

X.X. and Y.L. designed and performed the experiments, analysed the data, generated the figures and wrote the manuscript. L.C., H.Z., H.L., and J.J. helped with the data interpretation, discussed the hypotheses and participated in the manuscript preparation. Y.Y. designed and performed the experiments, helped with the data interpretation, participated in the data analysis and wrote the manuscript. W.B. supervised the project, designed the experiments, helped with the data interpretation, participated in the data analysis and wrote the manuscript. The authors read and approved the final manuscript.

\section{Funding}

This work was supported by grants from the Natural Science Foundation Team Project of Guangdong Province (2018B030312009), the National Natural Science Foundation of China (82070574, U1501224), and the Science and Technology Developmental Special Foundation of Guangdong Province (2017B020226003).

\section{Availability of data and materials}

The data in the current study are available from the corresponding authors upon reasonable request.

\section{Declarations}

\section{Ethics approval and consent to participate}

Study protocols were approved by the Ethics Committee of the Third Affiliated Hospital of Sun Yat-Sen University. Informed consent was obtained from all of the participants included in this study according to the committee regulations. All animal experiments and relevant details were conducted 
in accordance with the approved guidelines and were approved by the committee on Animal Care and Use of Sun Yat-Sen University.

\section{Consent for publication}

Not applicable.

\section{Competing interests}

The authors declare that they have no competing interests.

\section{Author details}

${ }^{1}$ Department of Gastroenterology, the Third Affiliated Hospital of Sun Yat-Sen University, Guangzhou 510630, Guangdong Province, China. Guangdong Provincial Key Laboratory of Liver Disease Research, Guangzhou 510630, Guangdong Province, China.

\section{Received: 29 April 2021 Accepted: 6 August 2021}

\section{Published online: 11 August 2021}

\section{References}

1. Laursen L. A preventable cancer. Nature. 2014;516(7529):S2-3. https://doi. org/10.1038/516S2a.

2. Llovet JM, Ricci S, Mazzaferro V, Hilgard P, Gane E, Blanc JF, et al. Sorafenib in advanced hepatocellular carcinoma. N Engl J Med. 2008;359(4):378-90 https://doi.org/10.1056/NEJMoa0708857.

3. Kuper $\mathrm{H}$, Adami HO, Trichopoulos D. Infections as a major preventable cause of human cancer. J Intern Med. 2000;248(3):171-83 https://doi.org/1 0.1046/j.1365-2796.2001.00742.x.

4. Karin M, Cao Y, Greten FR, Li ZW. NF-kappaB in cancer: from innocent bystander to major culprit. Nat Rev Cancer. 2002;2(4):301-10 https://doi. org/10.1038/nrc780.

5. Taniguchi K, Karin M. NF-kappaB, inflammation, immunity and cancer: coming of age. Nat Rev Immunol. 2018;18(5):309-24 https://doi.org/10.103 8/nri.2017.142

6. Luedde T, Schwabe RF. NF-kappaB in the liver--linking injury, fibrosis and hepatocellular carcinoma. Nat Rev Gastroenterol Hepatol. 2011;8(2):108-18 https://doi.org/10.1038/nrgastro.2010.213.

7. Baud V, Karin M. Is NF-kappaB a good target for cancer therapy? Hopes and pitfalls. Nat Rev Drug Discov. 2009;8(1):33-40 https://doi.org/10.1038/nrd2 781.

8. Greten FR, Eckmann L, Greten TF, Park JM, Li ZW, Egan LJ, et al. IKKbeta links inflammation and tumorigenesis in a mouse model of colitis-associated cancer. Cell. 2004;118(3):285-96 https://doi.org/10.1016/j.cell.2004.07.013.

9. Block TM, Mehta AS, Fimmel CJ, Jordan R. Molecular viral oncology of hepatocellular carcinoma. Oncogene. 2003;22(33):5093-107 https://doi.org/1 0.1038/sj.onc.1206557.

10. Grivennikov SI, Karin M. Inflammatory cytokines in cancer: tumour necrosis factor and interleukin 6 take the stage. Ann Rheum Dis. 2011;70(Suppl 1): i104-8 https://doi.org/10.1136/ard.2010.140145.

11. Luo JL, Maeda S, Hsu LC, Yagita H, Karin M. Inhibition of NF-kappaB in cancer cells converts inflammation- induced tumor growth mediated by TNF-alpha to TRAlL-mediated tumor regression. Cancer Cell. 2004;6(3):297305 https://doi.org/10.1016/j.ccr.2004.08.012.

12. Komatsu H, Fukuchi M, Habata Y. Potential utility of biased GPCR signaling for treatment of psychiatric disorders. Int J Mol Sci. 2019;20(13):3207 https:// doi.org/10.3390/ijms20133207.

13. Lefkowitz RJ, Shenoy SK. Transduction of receptor signals by beta-arrestins Science. 2005;308(5721):512-7 https://doi.org/10.1126/science.1109237.

14. Witherow DS, Garrison TR, Miller WE, Lefkowitz RJ. $\beta$-Arrestin inhibits NFkappaB activity by means of its interaction with the NF-kappaB inhibitor IkappaBalpha. Proc Natl Acad Sci U S A. 2004;101(23):8603-7 https://doi. org/10.1073/pnas.0402851101.

15. Luttrell LM, Miller WE. Arrestins as regulators of kinases and phosphatases. Prog Mol Biol Transl Sci. 2013;118:115-47 https://doi.org/10.1016/B9780-12-394440-5.00005-X

16. Yang Y, Guo Y, Tan S, Ke B, Tao J, Liu H, et al. $\beta$-Arrestin1 enhances hepatocellular carcinogenesis through inflammation-mediated Akt signalling. Nat Commun. 2015;6:7369 https://doi.org/10.1038/ncomms8369.

17. Dasgupta P, Rizwani W, Pillai S, Davis R, Banerjee S, Hug K, et al. ARRB1mediated regulation of E2F target genes in nicotine-induced growth of lung tumors. J Natl Cancer Inst. 2011;103(4):317-33 https://doi.org/10.1093/ jnci/djq541.
18. Li T, Alemayehu M, Aziziyeh Al, Pape C, Pampillo M, Postovit LM, et al. Beta-arrestin/Ral signaling regulates lysophosphatidic acid-mediated migration and invasion of human breast tumor cells. Mol Cancer Res. 2009; 7(7):1064-77 https://doi.org/10.1158/1541-7786.MCR-08-0578.

19. Manning BD, Toker A. AKT/PKB signaling: navigating the network. Cell. 2017; 169(3):381-405 https://doi.org/10.1016/j.cell.2017.04.001.

20. Fang G, Zhang P, Liu J, Zhang X, Zhu X, Li R, et al. Inhibition of GSK-3beta activity suppresses HCC malignant phenotype by inhibiting glycolysis via activating AMPK/mTOR signaling. Cancer Lett. 2019;463:11-26 https://doi. org/10.1016/j.canlet.2019.08.003.

21. Ke B, Zhao Z, Ye X, Gao Z, Manganiello V, Wu B, et al. Inactivation of NFkappaB p65 (RelA) in liver improves insulin sensitivity and inhibits CAMP/ PKA pathway. Diabetes. 2015;64(10):3355-62 https://doi.org/10.2337/db150242.

22. Qiu W, Wang X, Leibowitz B, Yang W, Zhang L, Yu J. PUMA-mediated apoptosis drives chemical hepatocarcinogenesis in mice. Hepatology. 2011; 54(4):1249-58 https://doi.org/10.1002/hep.24516.

23. Colomer C, Marruecos L, Vert A, Bigas A, Espinosa L. NF-kB members left home: NF-kB-independent roles in cancer. Biomedicines. 2017;5(2):26 https://doi.org/10.3390/biomedicines5020026.

24. Hatano E, Brenner DA. Akt protects mouse hepatocytes from TNF-alphaand Fas-mediated apoptosis through NK-kappa B activation. Am J Physiol Gastrointest Liver Physiol. 2001;281(6):G1357-68 https://doi.org/10.1152/a jpgi.2001.281.6.G1357.

25. Vainer GW, Pikarsky E, Ben-Neriah Y. Contradictory functions of NF-kappaB in liver physiology and cancer. Cancer Lett. 2008;267(2):182-8 https://doi. org/10.1016/j.canlet.2008.03.016.

26. Maeda S, Kamata H, Luo JL, Leffert H, Karin M. IKKbeta couples hepatocyte death to cytokine-driven compensatory proliferation that promotes chemical hepatocarcinogenesis. Cell. 2005;121(7):977-90 https://doi.org/10.1 016/j.cell.2005.04.014.

27. Pikarsky E, Porat RM, Stein I, Abramovitch R, Amit S, Kasem S, et al. NFkappaB functions as a tumour promoter in inflammation-associated cancer. Nature. 2004;431(7007):461-6 https://doi.org/10.1038/nature02924.

28. Finkin S, Yuan D, Stein I, Taniguchi K, Weber A, Unger K, et al. Ectopic lymphoid structures function as microniches for tumor progenitor cells in hepatocellular carcinoma. Nat Immunol. 2015;16(12):1235-44 https://doi. org/10.1038/ni.3290.

29. Sakurai T, Maeda S, Chang L, Karin M. Loss of hepatic NF-kappa B activity enhances chemical hepatocarcinogenesis through sustained c-Jun Nterminal kinase 1 activation. Proc Natl Acad Sci U S A. 2006;103(28):1054451 https://doi.org/10.1073/pnas.0603499103.

30. Luedde T, Beraza N, Kotsikoris V, van Loo G, Nenci A, Vos RD, et al. Deletion of NEMO/IKKgamma in liver parenchymal cells causes steatohepatitis and hepatocellular carcinoma. Cancer Cell. 2007;11(2):119-32 https://doi.org/10.1 016/j.ccr.2006.12.016.

31. Geisler F, Algül H, Paxian S, Schmid RM. Genetic inactivation of RelA/p65 sensitizes adult mouse hepatocytes to TNF-induced apoptosis in vivo and in vitro. Gastroenterology. 2007;132(7):2489-503 https://doi.org/10.1053/j.ga stro.2007.03.033

32. He G, Karin M. NF-kappaB and STAT3 - key players in liver inflammation and cancer. Cell Res. 2011;21(1):159-68 https://doi.org/10.1038/cr.2010.183.

33. Koppe C, Verheugd P, Gautheron J, Reisinger F, Kreggenwinkel K, Roderburg C, et al. IkappaB kinasealpha/beta control biliary homeostasis and hepatocarcinogenesis in mice by phosphorylating the cell-death mediator receptor-interacting protein kinase 1. Hepatology. 2016;64(4):1217-31 https://doi.org/10.1002/hep.28723.

34. Khandekar MJ, Cohen P, Spiegelman BM. Molecular mechanisms of cancer development in obesity. Nat Rev Cancer. 2011;11(12):886-95 https://doi. org/10.1038/nrc3174.

35. Zha L, Chen J, Sun S, Mao L, Chu X, Deng H, et al. Soyasaponins can blunt inflammation by inhibiting the reactive oxygen species-mediated activation of PI3K/Akt/NF-KB pathway. PLoS One. 2014;9(9):e107655 https://doi.org/1 0.1371/journal.pone.0107655.

36. Ghosh-Choudhury N, Mandal CC, Ghosh-Choudhury N, Ghosh CG. Simvastatin induces derepression of PTEN expression via NFkappaB to inhibit breast cancer cell growth. Cell Signal. 2010;22(5):749-58 https://doi. org/10.1016/j.cellsig.2009.12.010.

37. Peterson YK, Luttrell LM. The diverse roles of Arrestin scaffolds in G proteincoupled receptor signaling. Pharmacol Rev. 2017;69(3):256-97 https://doi. org/10.1124/pr.116.013367. 
38. Bagnato A, Rosanò L. New routes in GPCR/beta-Arrestin-driven signaling in Cancer progression and metastasis. Front Pharmacol. 2019;10:114 https:// doi.org/10.3389/fphar.2019.00114.

39. Cianfrocca R, Tocci P, Semprucci E, Spinella F, Di Castro V, Bagnato A, et al. $\beta$-Arrestin 1 is required for endothelin-1-induced NF-KB activation in ovarian cancer cells. Life Sci. 2014;118(2):179-84 https://doi.org/10.1016/j.lfs.2014.01. 078.

40. Hoeppner CZ, Cheng N, Ye RD. Identification of a nuclear localization sequence in beta-arrestin-1 and its functional implications. J Biol Chem. 2012;287(12):8932-43 https://doi.org/10.1074/jbc.M111.294058.

41. Lo Re O, Fusilli C, Rappa F, Van Haele M, Douet J, Pindjakova J, et al. Induction of cancer cell stemness by depletion of macrohistone H2A1 in hepatocellular carcinoma. Hepatology. 2018;67(2):636-50 https://doi.org/10.1 002/hep.29519.

\section{Publisher's Note}

Springer Nature remains neutral with regard to jurisdictional claims in published maps and institutional affiliations.

Ready to submit your research? Choose BMC and benefit from:

- fast, convenient online submission

- thorough peer review by experienced researchers in your field

- rapid publication on acceptance

- support for research data, including large and complex data types

- gold Open Access which fosters wider collaboration and increased citations

- maximum visibility for your research: over $100 \mathrm{M}$ website views per year

At $\mathrm{BMC}$, research is always in progress.

Learn more biomedcentral.com/submissions 